\title{
Wing morphological responses to latitude and colonisation in a range expanding butterfly
}

\author{
Evelyn D Taylor-Cox ${ }^{\text {Corresp., } 1}$, Callum J Macgregor ${ }^{2,3}{ }^{,}$Amy Corthine $^{1}{ }^{1}$, Jane K Hill ${ }^{2}$, Jenny A Hodgson ${ }^{1}$, Ilik J Saccheri \\ 1 Department of Evolution, Ecology and Behaviour, University of Liverpool, Liverpool, United Kingdom \\ 2 Leverhulme Centre for Anthropocene Biodiversity, Department of Biology, University of York, York, United Kingdom \\ 3 Energy and Environment Institute, University of Hull, Hull, United Kingdom \\ Corresponding Author: Evelyn D Taylor-Cox \\ Email address: e.taylorcox@hotmail.co.uk
}

Populations undergoing rapid climate-driven range expansion experience distinct selection regimes dominated both by increased dispersal at the leading edges and steep environmental gradients. Characterisation of traits associated with such expansions provides insight into the selection pressures and evolutionary constraints that shape demographic and evolutionary responses. Here we investigate patterns in three components of wing morphology (size, shape, colour) often linked to dispersal ability and thermoregulation, along latitudinal gradients of range expansion in the Speckled Wood butterfly (Pararge aegeria) in Britain (two regions of expansion in England and Scotland). We measured 774 males from 54 sites spanning $799 \mathrm{~km}$ with a 10 -year mean average temperature gradient of $4^{\circ} \mathrm{C}$. A geometric morphometric method was used to investigate variation in size and shape of forewings and hindwings; colour, pattern, and contrast of the wings were examined using a measure of lightness (inverse degree of melanism). Overall, wing size increased with latitude by $\sim 2 \%$ per $100 \mathrm{~km}$, consistent with Bergmann's rule. Forewings became more rounded and hindwings more elongated with history of colonisation, possibly reflecting selection for increased dispersal ability. Contrary to thermal melanism expectations, wing colour was lighter where larvae developed at cooler temperatures and unrelated to long-term temperature. Changes in wing spot pattern were also detected. High heterogeneity in variance among sites for all of the traits studied may reflect evolutionary time-lags and genetic drift due to colonisation of new habitats. Our study suggests that temperature-sensitive plastic responses for size and colour interact with selection for dispersal traits (wing size and shape). Whilst the plastic and evolutionary responses may in some cases act antagonistically, the rapid expansion of $P$. aegeria implies an overall reinforcing effect between these two mechanisms. 


\section{Wing morphological responses to latitude and}

\section{2 colonisation in a range expanding butterfly}

3

4 Evelyn D. Taylor-Cox ${ }^{1}$, Callum J. Macgregor ${ }^{2,3}$, Amy Corthine ${ }^{1}$, Jane K. Hill², Jenny A.

5 Hodgson $^{1}$, Ilik J. Saccheri ${ }^{1}$

6

$7 \quad{ }^{1}$ Department of Evolution, Ecology and Behaviour, University of Liverpool, Liverpool, UK

$8{ }^{2}$ Leverhulme Centre for Anthropocene Biodiversity, Department of Biology, University of York,

9 York, UK

$10 \quad{ }^{3}$ Energy and Environment Institute, University of Hull, Hull, UK

11

12 Corresponding Author:

13 Evelyn D. Taylor-Cox ${ }^{1}$

14 Biosciences Building, University of Liverpool, Liverpool, L69 7BE

15 Email address: e.taylor-cox@liverpool.ac.uk

\section{ORCID IDs}

19 Evelyn D. Taylor-Cox: 0000-0002-3937-3643

20 Callum Macgregor: 0000-0001-8281-8284

21 Amy Corthine: 0000-0002-1155-6106

22 Jane K. Hill: 0000-0003-1871-7715

23 Jenny A. Hodgson: 0000-0003-2297-3631

24 Ilik J. Saccheri: 0000-0003-0476-2347 


\section{Abstract}

29 Populations undergoing rapid climate-driven range expansion experience distinct selection regimes dominated both by increased dispersal at the leading edges and steep environmental gradients. Characterisation of traits associated with such expansions provides insight into the selection pressures and evolutionary constraints that shape demographic and evolutionary responses. Here we investigate patterns in three components of wing morphology (size, shape, colour) often linked to dispersal ability and thermoregulation, along latitudinal gradients of range expansion in the Speckled Wood butterfly (Pararge aegeria) in Britain (two regions of expansion in England and Scotland). We measured 774 males from 54 sites spanning $799 \mathrm{~km}$ with a 10 -year mean average temperature gradient of $4^{\circ} \mathrm{C}$. A geometric morphometric method was used to investigate variation in size and shape of forewings and hindwings; colour, pattern, and contrast of the wings were examined using a measure of lightness (inverse degree of melanism). Overall, wing size increased with latitude by $\sim 2 \%$ per $100 \mathrm{~km}$, consistent with

41 Bergmann's rule. Forewings became more rounded and hindwings more elongated with history 42 of colonisation, possibly reflecting selection for increased dispersal ability. Contrary to thermal melanism expectations, wing colour was lighter where larvae developed at cooler temperatures and unrelated to long-term temperature. Changes in wing spot pattern were also detected. High heterogeneity in variance among sites for all of the traits studied may reflect evolutionary timelags and genetic drift due to colonisation of new habitats. Our study suggests that temperaturesensitive plastic responses for size and colour interact with selection for dispersal traits (wing size and shape). Whilst the plastic and evolutionary responses may in some cases act antagonistically, the rapid expansion of $P$. aegeria implies an overall reinforcing effect between these two mechanisms. 


\section{Introduction}

54 A population may respond to climate change either by altering its phenotype to maintain local 55 fitness, or by shifting distribution and/or phenology to track its climatic envelope (Parmesan \& Yohe, 2003; Macgregor et al., 2019). During a range expansion populations on the range front are subject to multiple selection pressures (Phillips, Brown \& Shine, 2010). Any resulting phenotypic changes are therefore created by evolutionary responses to both changing local environments and the process of range expansion itself. Phenotype-environment optima under equilibrium conditions, may be overridden or obscured by the expansion process as mal-adapted genotypes can surf on the range front due to genetic drift (Burton \& Travis, 2008). Moreover, temperature-dependent reaction norms, and genetic correlations among traits, may help or hinder adaptation to the new environment (Pujol et al., 2018). Phenotypic responses to climate change have been reported for correlates of dispersal (Thomas et al., 2001; Hill, Griffiths \& Thomas, 2011), body size (Daufresne, Lengfellner \& Sommer, 2009), and colour lightness (linked to thermal tolerance; Zeuss et al., 2014).

Contemporary evolution of dispersal traits is often closely linked to the process of range shifts towards cooler climates (Parmesan, 2006; Hickling et al., 2006). Indeed, a common phenotypic signature of range expansion, found in many species, is increased dispersal ability towards the leading edge of a shifting range (Hughes, Hill \& Dytham, 2003; Simmons \& Thomas, 2004; Phillips, Anderson \& Schapire, 2006). This cline in dispersal ability is a product of spatial selection, resulting from the combined effects of spatial sorting (assortative mating of dispersive genotypes on the range edge) and density-dependent selection (Phillips, Brown \& Shine, 2010). Density-dependent selection is predicted to favour good dispersers colonising new habitat patches, where they encounter much lower intraspecific competition, resulting in increased fecundity and intrinsic growth rates at the range edge. Dispersal in insects, of which flight performance is a key component, may be affected by several factors including morphological, physiological, metabolic, and behavioural traits (Betts \& Wootton, 1988; Berwaerts, Van Dyck \& Aerts, 2002; Niitepõld et al., 2009; Flockhart et al., 2017; Renault, 2020). Thorax size (highly correlated to whole body size) is a widely accepted measure of dispersal ability in Lepidoptera as

82 it indicates flight muscle investment (Srygley \& Chai, 1990; Hill, Thomas \& Lewis, 1999; 
83 Berwaerts, Van Dyck \& Aerts, 2002). Wing size has been shown to be correlated with body size 84 measurements (e.g., thorax size, body length and dry mass) in several Lepidoptera species (Chai 85 \& Srygley, 1990; Merckx \& Van Dyck, 2006) and hence can be used as a proxy for overall size 86 and dispersal (Sekar, 2012). Wing shape has direct implications for aerodynamics during flight, 87 which affects the efficiency of flight strategies, flight ability and dispersal (Breuker, Brakefield 88 \& Gibbs, 2007; Le Roy, Debat \& Llaurens, 2019).

89

90 Morphological trends associated with poleward range expansion could be due to spatial selection 91 for dispersal ability, but could also reflect a genetic or plastic response to an environmental cline.

92 One such phenotype-environment relationship is an increase in body size with latitude

93 (Bergmann's rule; Bergmann, 1848). Originally described in mammals, this pattern (and its 94 converse) has been observed in ectotherms (Shelomi, 2012). Bergmann clines often suggest 95 genetic adaptation to different thermal environments but phenotypic plasticity also plays an important role in producing body size clines (Atkinson \& Sibly, 1997; Mousseau, 2006). The temperature size rule, describes the plastic response of body size to developmental temperature (smaller individuals at higher temperatures) in ectotherms (Atkinson, 1994). However, selection for increased size at lower temperature is not supported across all species (Stillwell, Moya-lara \&

100 Fox, 2008), and the relationship of size to temperature may evolve in different directions

101 between recently divergent populations that experience contrasting temperature regimes

102 (Kingsolver et al., 2007). Body size clines in ectotherms are further affected by season length 103 and voltinism, i.e. the number of generations per year, as growing time is positively correlated to 104 size (Chown \& Gaston, 2010; Horne, Hirst \& Atkinson, 2015; Zeuss, Brunzel \& Brandl, 2017). 105 Above a certain latitude, shortening of season length reaches a point where the limited time 106 available for development, growth and foraging results in reduced overall body size with 107 latitude, i.e. a converse Bergmann cline (Blanckenhorn \& Demont, 2004). The addition of a 108 second-generation can result in complex saw-tooth patterns of body size with season length 109 (Roff, 1980). Season length and voltinism may therefore explain why both the inverse and 110 classical Bergmann's rule have been documented in arthropods (Horne, Hirst \& Atkinson, 2015), 111 suggesting that these patterns are not contradictory but part of a continuum (Blanckenhorn \& 112 Demont, 2004). 
114 Melanism is another trait often associated with adaptation to the thermal environment (thermal

115 melanism). For example, in ectotherms darker species frequently occur at higher latitudes or in

116 cooler climates (Zeuss et al., 2014; Heidrich et al., 2018). This observation is often explained by

117 the thermal melanism hypothesis, which states that darker individuals have an advantage in

118 cooler climates (Clusella Trullas, van Wyk \& Spotila, 2007). In principle, all other things being

119 equal, ectotherms presenting a larger and/or darker surface area of melanised exocuticle should

120 show increased absorption of solar radiation compared to lighter individuals, thus reaching a

121 higher body temperature and at a faster rate. This could, in turn, allow activity at lower

122 temperatures, potentially enhancing mating opportunities (Clusella Trullas, van Wyk \& Spotila,

123 2007) and dispersal (Mattila, 2015). It has been suggested that the basal part of the wing is the

124 most important for thermal regulation (Wasserthal, 1975), but other components of the wing

125 pattern may contribute to the thermal properties of wings (Brashears, Aiello \& Seymoure, 2016).

126 Melanism also plays an important role in protection against UV radiation (Bishop et al., 2016;

127 Katoh, Tatsuta \& Tsuji, 2018) and pathogens (Dubovskiy et al., 2013), which may lead to darker

128 individuals in warmer climates, opposing the trend predicted by a purely thermal explanation.

129 The degree of melanism may also be affected by selection on the colour pattern which has

130 important functions in mate choice (Jiggins et al., 2001; Kemp, 2007) and predation avoidance

131 (Bond \& Kamil, 2002). Futhermore, seasonal polyphenism (the production of different

132 phenotypes in different seasonal generations) is widely documented in Lepidoptera, and

133 particularly prominent in multivoltine species (Kingsolver, 1995). This phenomenon is driven by

134 environmental cues (Roskam \& Brakefield, 1999), often altering wing pattern, which can

135 potentially produce pattern differences across environmental gradients.

136

137 In this study, the Speckled Wood butterfly (Pararge aegeria (Linnaeus, 1758)), which has

138 undergone rapid range expansion in mainland Britain, was used to investigate phenotypic

139 changes in wing size, shape and melanism, with respect to colonisation history, latitude and

140 temperature. Flight morphological traits in P. aegeria differ across latitudinal clines in mainland

141 Europe, by habitat type (Vandewoestijne \& van Dyck, 2010) and with mate location strategy

142 (Berwaerts, Van Dyck \& Aerts, 2002). Bergmann's rule has been reported for the British

143 population, with larger individuals found further north (Dennis \& Shreeve, 1989; Sibly, Winokur

144 \& Smith, 1997), whereas the inverse pattern was seen in Sweden (Nylin \& Svärd, 1991). An 
145 increase in dispersal ability, using thorax size as an indicator, was found towards the expanding

146 range edge in the UK, with a potential evolutionary trade-off between reproduction and dispersal

147 (Hughes, Hill \& Dytham, 2003). These studies of the British populations were limited to a

148 relatively small number of sites, when the distribution of $P$. aegeria in England and Scotland was

149 much less extensive. Detailed analysis of $P$. aegeria wing morphology, especially using

150 geometric morphometrics, across the range expansion in Britain is lacking. Dennis and Shreeve

151 (1989) report latitudinal variation in P. aegeria wing colour which is consistent with the

152 anecdotal perception of butterfly recorders that individuals from northerly populations tend to be

153 darker than those from southern populations. The cream spot pattern of $P$. aegeria has been

154 described to increase in lightness and size with latitude, possibly due to the interplay between

155 thermoregulatory requirements, mate choice and predator escape (Dennis \& Shreeve, 1989).

156 However, to our knowledge, the qualitative perceptions of $P$. aegeria colour and pattern have not

157 been verified quantitatively.

158

159 Pararge aegeria in Britain provides an opportunity to examine the interplay and influence of

160 demographic factors (range expansion) and environmental factors (latitude and temperature, both

161 during development and in the recent past) in shaping morphological traits in a rapidly

162 expanding population. We investigated phenotypic changes in wing size and shape (linked to

163 dispersal ability and body size), as well as colour and pattern (potentially influencing

164 thermoregulation) across the expanded range of $P$. aegeria in mainland Britain. In common with

165 similar studies on wild-caught individuals that lack experimental and/or genetic data, our sample

166 does not allow strong inferences about the relative importance of phenotypic plasticity vs.

167 genotypic differences in determining the observed patterns in morphological variation. The

168 relative effect of demographic and environmental factors on morphology were evaluated through

169 collection of samples along the axes of range expansion, specifically to capture a wide range of

170 local population ages and colonisation histories (from core sites known to have been

171 continuously occupied at least since 1965 to leading edge sites colonised in 2015), as well as

172 over large gradients in latitude (covering a distance of $799 \mathrm{~km}$ ), mean 10-year annual temperature

$173\left(4^{\circ} \mathrm{C}\right)$ and mean temperature during development $\left(6^{\circ} \mathrm{C}\right)$. We hypothesised that: 1$)$ wing size is

174 larger in more recently colonised populations, as predicted by spatial selection; 2) wing size

175 increases with latitude, following Bergmann's and the temperature-size rules; 3) wing size is 
176 smaller in populations with more generations; 4) wing shape changes to a more dispersive form 177 with colonisation history; 5) melanism increases with latitude and decreasing temperatures, in 178 accordance with the thermal melanism hypothesis; and 6) the cream spot wing pattern becomes 179 lighter and larger with latitude, as described by Dennis \& Shreeve (1989). 
181

\section{Materials \& Methods}

\section{Study species and sample collection}

184 Pararge aegeria is a multivoltine species (capable of completing multiple generations in a year)

185 which occurs throughout Europe to western Asia. Pararge aegeria can follow three different

186 developmental pathways - pupal diapause, larval diapause or direct development - that may

187 differentially affect morphology (Van Dyck \& Wiklund, 2002). Within the UK, the range of $P$.

188 aegeria has changed dynamically in the past 200 years. At the end of the $19^{\text {th }}$ century there was a

189 contraction of populations to south-west England, Wales and a refuge population in western

190 Scotland, assumed to be in response to a change in climate (Emmet \& Heath, 1990; Warren et

191 al., 2001). Since the 1970s, the distribution of P. aegeria began to expand northwards from

192 south-west England and Wales, argued to be mainly driven by increasing temperatures, but also

193 other factors such as habitat preference. A secondary range expansion from the refuge population

194 in western Scotland has recolonised much of central and northern Scotland. Increased habitat

195 fragmentation of woodland habitats resulted in a greater than expected lag in the rate of range

196 expansion compared to the climatic envelope (Hill, Thomas \& Huntley, 1999). P. aegeria is now

197 widespread across the UK.

198

199 A total of 774 male $P$. aegeria were hand netted across 54 sites (10-20 males/site) during the summers of 2016-2018 in the UK (Fig 1; Table S1). In order to capture the pattern of range

201

202

203

204

205

206

207

208

209

210 expansion, the site locations were chosen at a $10 \mathrm{~km}$ grid scale aimed, firstly, at covering the whole of the geographic range and, secondly, to include the full range of number of years since P. aegeria was first recorded at $10 \mathrm{~km}$ grid resolution. Specimens collected in 2018 were frozen on or the day after collection using a liquid nitrogen dry shipper and subsequently transferred to $80^{\circ} \mathrm{C}$ freezer for storage. Samples collected in 2016/17 were kept alive in a cool box for two days until transfer to a $-80^{\circ} \mathrm{C}$ freezer. Permission for sampling at sites was obtained from landowners, including, but not limited to: Natural England, National Trust, Forestry Commission (England and Scotland), Woodland Trust, Yorkshire Wildlife Trust, Norfolk Wildlife Trust, local councils and site rangers through correspondence and verbal communication. 


\section{Photography}

212 Wings were carefully removed from the body at their point of attachment using fine scissors. The

213 photographic setup consisted of Nikon D80 with Micro-Nikkor 40mm lens attached to a camera

214 stand, and two stand-alone speedlight (YN560IV) flashes (ISO 160, aperture f/25, exposure time

215 of 1/80 seconds and compensation level +5.0$)$. Size and shape analyses were carried out on jpeg

216 files, but for colour analysis, to retain more information, images were converted from RAW

217 Nikon images (NEF) to portable network graphics (png) using the programme XnConvert v.1.82.

218 Photographs were calibrated by the R package Patternize (Van Belleghem et al., 2018), using the

219 ColorGauge Micro Target (Image Science Associates) to account for any changes in lighting

220 (Fig.2A). Wings were graded into four wear categories, both for physical damage and scale

221 damage (1= no damage, $4=$ significant/total damage). The sum of these two factors, assumed to

222 be loosely correlated with butterfly age, was used as a factor in the analyses, or as a filter to

223 remove significantly damaged and old butterflies. The left wings were selected as a priority for

224 analysis, but if significant damage was present the right side was used instead.

\section{Environmental and demographic variables}

227 We focused on four demographic or environmental variables: 1) number of years since first

228 record or colonisation (years colonised); 2) latitude; 3) mean temperature during development;

229 and 4) 10-year mean annual temperature.

231 To determine if developmental temperature accounts for any differences in morphology,

232 latitudinal variation in emergence peaks had to be taken into account, due to $P$. aegeria being a

233 multivoltine species. The specimens in this study were mainly collected late May - early August,

234 which generally corresponds to the start of the second generation. However, more southerly

235 populations emerge earlier in the summer and undergo more generations than those further north.

236 Therefore, the emergence patterns of each 10km grid sampled, based on 10-year abundance data

237 from the Butterflies for the New Millennium (BNM) recording scheme (2007-2017), was

238 investigated using generalised additive models, in the R package mgcv (Wood, 2004). This

239 allowed identification of the number of generations at each grid, and the month of the second-

240 generation peak. To assess the effect of temperature during embryo, larva and pupa development

241 on morphological traits, we used the average temperature of the local second-generation peak 
242 month and the preceding two months, in the year of collection (e.g., for a site with a second

243 generation peak in June, the mean temperature during development was calculated as the mean

244 of April- June in the collection year).

245

246 To investigate potential morphological responses to multi-generational selection related to

247 geographic variation in temperature, we used 10-year mean annual temperature $\left(T_{10}\right)$, at $1 \mathrm{~km}$

248 resolution, from the year prior to collection (e.g., for a butterfly sample collected in $2018, \mathrm{~T}_{10}$

249 was calculated from 2007-2017). Ten years was chosen as a suitable timescale for phenotypic

250 response to selection, even for more recently colonised populations, whilst reducing the effect of

251 any large fluctuations in annual temperature. Temperature (monthly mean at a $1 \mathrm{~km}$ resolution)

252 data for 2007-2017 were obtained from the Met Office HadUK-Grid UKCP18 dataset, available

253 through CEDA Archives. 2018 data were provided directly by the UK Met Office.

254

255 The pattern of range expansion was described by the number of years since the first record of $P$.

256 aegeria at each $10 \mathrm{~km}$ grid (referred to as years colonised), using distribution data from the BNM

257 from 1965 onwards. The reliability of this type of data as an accurate reflection of changes in

258 species distribution relies on recorder effort and geographic coverage of records across the UK.

259 Previous studies that have accounted for recorder effort reveal that the expansion of P. aegeria is

260 a true occurrence and not due to changes in recorder effort (Parmesan et al., 1999). To assess the

261 reliability of the assumed pattern of expansion we applied an approach used in Macgregor et al.

262 (2019). For each grid, the percentage of regional species richness recorded was calculated (using

263 data for 58 butterfly species provided by BNM, where regional species richness was the total

264 number of species recorded in the 100 nearest neighbouring grids) in each year between 1965-

265 2014. Grids were considered well-recorded in a given year if 10\% or more of regional species

266 richness was recorded. We then used this recording level to determine the level of confidence for

267 the year each $10 \mathrm{~km}$ grid was colonised by $P$. aegeria. Grids in which P. aegeria was recorded

268 prior to 1975 were considered to be part of the core range of the species. From the remaining

269 grids, we considered that we had high confidence of the colonisation year for grids which had

270 been well-recorded in at least three years prior to the first record of P. aegeria (i.e. probable

271 absence, followed by presence). We considered that we had low confidence of the colonisation

272 year for grids in which the first record of $P$. aegeria coincided with or preceded the onset of 
273 good recording (i.e. P. aegeria first recorded in or before the third well-recorded year), since it 274 was unclear whether such records represented true colonisation or simply the discovery of pre-

275 existing populations. The reported pattern of range expansion is evident even when core and high 276 confidence grids are considered in isolation (Fig.1), showing that it is not an artifact of increased 277 or changing patterns of recorder effort. Furthermore, the majority of sites sampled are from $27810 \mathrm{~km}$ grids that are categorised as core or high confidence sites, supporting our use of 'years 279 colonised' as an accurate metric for the sites studied.

\section{Wing landmarking and morphometrics}

282 To allow for comparison of geometric morphometry and pattern across individuals, 14 and 11

283 landmarks were digitised on the forewing and hindwing, respectively, using tpsUtil version 1.78 284 (Rohlf, 2019) and tpsDig2 version 2.31 (Rohlf, 2017). All landmarks were placed on vein-vein 285 or vein-wing margin intersections and provided adequate coverage of the overall shape and 286 internal structure of the wings (Fig.2). Landmarks were superimposed using generalised

287 Procrustes analysis performed using the R package geomorph (Adams \& Otárola-Castillo, 2013) 288 and within MorphoJ version 1.07a (Klingenberg, 2011). This method standardises specimens to a 289 common coordinate system through controlling size, orientation and position to align 290 corresponding landmarks as closely as possible (Rohlf \& Slice, 1990). Centroid size (CS) was 291 also calculated from the landmarks (square root of the sum of squared distances between each 292 landmark and the wing centroid), and was used as a measure of wing size and to account for 293 allometry in the analysis of wing shape.

\section{Size analysis}

296 Linear mixed effect models (LMM) fitted by restricted maximum likelihood (lme4 v.1.1-21

297 package; Bates et al., 2014), with bobyqa optimisation, was used to assess the effect of the four 298 environmental factors on wing size, quantified as CS. Random effects included were: 1) site 299 (10km grid) nested within regional expansion (i.e., south-west England or western Scotland), to 300 account for variation amongst sites and expansions, and 2) number of Julian days before or after 301 the peak of the second generation at a 10km scale that the sample was collected on (referred to as 302 the standardised collection date). Correlation of explanatory variables was investigated in $\mathrm{R}$ with 
303 scatterplots and the Pearson correlation coefficient. The effect of voltinism on wing size was

304 tested using a two-sample t-test.

305

306 Significance testing for LMMs is not straightforward, as the denominator for degrees of freedom

307 is difficult to obtain for models with multiple levels (Baayen, Davidson \& Bates, 2008);

308 therefore the package lme4 does not produce p-values (Bates et al., 2015). Instead, the t-value

309 from the LMM indicates the strength of the effect and some authors suggest a t-value of

310 magnitude over 1.96 can be considered significant, following the $t$-as- $z$ approach (Luke, 2017).

311 Therefore, traditional p-values are not presented for LMMs in this study, and a t-value with a

312 magnitude of 1.96 or above is considered significant.

313

314 Shape analysis

315 To investigate shape changes, independently of size, a multivariate regression of the Prosecutes

316 coordinates against wing size ( $\log$ CS) was carried out (10,000 permutations). This method

317 accounts for allometric patterns by producing a regression score that corresponds to the shape

318 variable with the greatest covariation to size. The residuals of this regression can therefore be

319 treated as a size-adjusted shape variable. This method has been used widely to account for

320 allometry in many morphometric studies (van Heteren et al., 2016; Curth, Fischer \& Kupczik,

321 2017). An analysis of covariance (ANCOVA) was used to determine if allometry was

322 significantly different between forewings and hindwings.

323

324 The resulting size-adjusted variables were then used for a two-block partial least squares (2B-

325 PLS) method across all individuals (Rohlf \& Corti, 2000). The 2B-PLS method aims to capture

326 the greatest amount of covariation between two blocks of variables (here size-adjusted shape as

327 block one, and environmental variables as block two) of equal weight. This method calculates a

$328 \mathrm{RV}$ coefficient, that can be interpreted as a multivariate generalization of the bivariate $\mathrm{R}^{2}$, and

329 used to determine the strength of the covariation between blocks (Klingenberg, 2009). A

330 permutation test (10,000 repetitions) was used to compare the observed association against the

331 null hypothesis of complete independence. Shape changes associated with PLS axes are shown

332 using wireframe diagrams against the mean (or consensus) wing shape. All 2B-PLS analyses 
333 were carried out in MorphoJ v1.07a (Klingenberg, 2011) and plotted with ggplot2 (Wickham, 334 2016).

335

336 Wing colour, pattern and contrast

337 Pararge aegeria wings are brown with a principally cream spot pattern. Four complementary

338 measures of colour and pattern were investigated: 1) average degree of lightness across the basal

$3393^{\text {rd }}$ and entire wing surfaces (dorsal and ventral surfaces on forewing and hindwing); 2) average

340 lightness within brown and cream areas (forewing dorsal only); 3) the relative area of brown and

341 cream (forewing dorsal only); and 4) the contrast between brown to cream areas (forewing dorsal

342 only).

343

344 Degree of lightness of the forewing and hindwing dorsal and ventral surfaces was investigated

345 using the mean grey value for the whole wing and the basal third of the wing, closest to the body

346 (basal colour). It has been suggested that wing basal colour is the most important for thermal

347 regulation (Wasserthal, 1975). An ImageJ (FiJi distribution) macro was created to select the

348 individual wings from the background, rotate them to the same orientation, separate wings into

349 thirds (perpendicular to the longest axis), convert RGB images to 8-bit grey, and calculate the

350 mean grey value for the whole wing and each wing section. The full 8-bit grey scale ranges from

3510 (complete black) to 255 (complete white). Wings with scale damage of 4 were removed from

352 the analysis, leaving 709 forewings and 642 hindwings. The effect of the environmental

353 variables on mean grey values was analysed in a LMM, fitted by restricted maximum likelihood

354 and $n m k b w$ optimisation (lme4 v.1.1-21 package; Bates et al., 2015). Site nested within regional

355 expansion (i.e., south-west England or western Scotland), and the standardised collection date

356 metric were included as random effects. Significance testing followed the method detailed for

357 size analysis.

358

359 To investigate variation in the brown and cream areas separately (dorsal forewing only as it has

360 the most discrete pattern), a macro script for ImageJ (FiJi distribution) was written to calculate

361 the mean grey value and area (number of pixels) for each (filtered for scale damage of 4). Linear

362 regression was used to assess the relationship of brown (or cream) area with latitude, and an

363 ANCOVA to determine if these relationships differed significantly from each other. The 
364 relationship of brown to cream colours in the forewing was quantified by linear regression on the 365 residuals of each colour to latitude (to focus on the underlying relationship). Finally, the

366 difference between the cream and brown mean grey value was calculated to produce a simple

367 measure of average contrast between the dark and light areas of the wing. The effect of the

368 environmental variables on contrast between brown and cream was analysed in a LMM, fitted by

369 restricted maximum likelihood and nmkbw optimisation (lme4 v.1.1-21 package; Bates et al.,

370 2015). The random effects included were the same as for the overall lightness analysis. 


\section{Results}

375 Wing morphometrics

376 Size

377 Forewing and hindwing size increase significantly with latitude (t-values $>1.96$ ) and in more

378 recently colonised populations (shown by negative relationship of size to an increase in number

379 of years colonised), consistent with Bergmann's rule and spatial selection. Forewing size is also

380 weakly associated with temperature during development $(\mathrm{t}=2.64)$ but not in hindwings $(\mathrm{t}=1.65)$.

381 In general, each of the environmental factors (latitude, years colonised, 10-year temperature

382 average, and temperature during development) show a consistent effect (both in the strength and 383 direction) on forewing and hindwing size, although latitude seems to have a stronger effect on

384 hindwings compared to forewings (Table 1; Fig.3). $\mathrm{T}_{10}$ (10-year mean annual temperature)

385 produced the lowest t-values $(0.57,0.58)$ across the environmental variables for both wings, 386 indicating no effect of recent past temperature on wing size. Correlation between explanatory

387 variables was considered acceptable for LMMs (Figure S1). The Pearson correlation coefficient 388 ranged between 0.14 (years colonised with temperature during development) to -0.74 (latitude

389 with mean annual temperature). Although latitude is often considered a proxy for annual

390 temperature, it also incorporates other environmental gradients that follow latitude, for example

391 day length and amount of sunlight etc. Therefore, it was decided to retain both $\mathrm{T}_{10}$ and latitude in 392 the model.

393

394 The populations varied between two and three generations per year across the $10 \mathrm{~km}$ grid 395 sampled, and size of forewings (mean CS of 2.60 (2 generations) and 2.55 (3 generations)) and 396 hindwings (mean CS of 2.39 (2 generations) and 2.33 (3 generations)) are significantly smaller 397 (1.9\% and 2.5\% smaller in forewings and hindwings, respectively) in populations with three 398 generations ( $\mathrm{t}$-test: $\mathrm{t}=4.96, \mathrm{df}=661.36, \mathrm{p}<0.001$ for forewing; $\mathrm{t}=4.45, \mathrm{df}=598.26, \mathrm{p}<0.001$ for 399 hindwing). 
401 Shape

402 Shape is significantly associated with size ( $\log$ CS) both for forewing and hindwing, reflecting 403 shape allometry $(\mathrm{p}<0.0001$; Fig. 4A). Allometry is less pronounced in the forewing, where the 404 regression explained $1.25 \%$ of shape variance compared to $4.14 \%$ in the hindwing (ANCOVA of 405 regressions, $\mathrm{F}=21.53, \mathrm{df}=1, \mathrm{p}<0.001$; slope of $1.31 \pm 0.14$ and $2.25 \pm 0.14$ respectively; Fig. $4 \mathrm{~A}$ and 406 4B). Shape changes for forewings and hindwings relative to size and the consensus shape are 407 shown in Figure 4C-F, respectively. Overall, larger wings have increased width and roundness 408 compared to smaller individuals. The shape difference between small and large forewings is 409 most noticeable for landmark 7, which moves further away from the consensus shape with 410 increasing size, and for landmark 1, which is shifted inwards, producing relatively broader and 411 shorter wings. In the hindwings, landmarks 5 and 11 are more separated from each other in large 412 hindwings, resulting in relatively wider wings compared to smaller hindwings.

413

414 The 2B-PLS analysis focused on covariation between the size-adjusted shape (block 1) and 415 environmental variables (block 2). Overall, the permutation test showed a significant covariation 416 between the two blocks both for the forewing $(\mathrm{p}=0.006)$ and hindwing $(\mathrm{p}=0.0001)$, supporting 417 non-independence of the two blocks. The overall strength of association between the two blocks 418 (as explained by the RV coefficient) is weak, at 0.012 and 0.025 , respectively. The first PLS axis 419 (PLS1) explained 73\% and 91\% for forewing and hindwing, respectively, and was principally 420 loaded by years colonised and latitude (for both wings), but showed a weak correlation ( 0.20 and 4210.22 respectively; Table 2; Fig. 5A and B). This suggests that, out of the environmental factors 422 studied, the range expansion process has the largest effect on shape. $\mathrm{T}_{10}$ was always loaded on 423 the fourth PLS axis, explaining the least variation across both wings, implying a minimal effect 424 of recent past temperature on wing shape.

425

426 Shape changes associated with PLS1 (associated most strongly with years colonised; Fig. 5C-F) 427 and the second PLS axis (PLS2; mainly latitude; not shown) indicate a general tendency towards 428 longer, narrower forewings (i.e., with increasing numbers of years colonised). Within PLS1 this 429 increase mainly occurs between the base or shoulder of the wing (landmark 1) to the apex

430 (landmarks 12-14), while the distance between landmark 1 and 7 decreases (Fig. 5C and 5D). In 431 comparison, the hindwing PLS1 (and PLS2) becomes more rounded. For PLS1, the increased 
432 roundness seems to be due to the majority of landmarks at the tail edge of the wing being more 433 separated from one another (Fig. 5E and 5F).

434

435 Colour, pattern and contrast

436 The average lightness (average grey value) of whole wing surfaces, whether dorsal or ventral,

437 has a complex relationship with latitude, with periodic fluctuations of lightness that are 438 consistent in the forewing and hindwing (Fig. 6). The relationship of average lightness with the 439 demographic and environmental variables are similar across the basal third of the wing (Table 3 ) 440 and whole wing (Table S2). The lightness of ventral surfaces, both of forewings and hindwings, 441 becomes significantly darker with increasing temperature during development, but significantly 442 lighter with increasing latitude (Table 3; greyness value of 0 is black and 255 is white). The 443 direction of effects is consistent among all four wing surfaces, although the trend is not 444 significant for dorsal surfaces. There is no detectable effect of $\mathrm{T}_{10}$ and years colonised on any 445 wing surfaces. These effects account for variation due to population (England or Scotland) and 446 sampling date.

447 The relationship between latitude and mean grey value of the dorsal forewing depends 448 significantly on the colour considered (ANCOVA, $F=27.69$, $\mathrm{df}=1, \mathrm{p}<0.001$ ). Both brown and 449 cream become significantly lighter with latitude $(\mathrm{p}<0.001)$, but the cream area becomes lighter 450 faster (i.e., further north) than the brown area (slopes of $3.38 \pm 0.25$ vs $1.49 \pm 0.26$ greyscale units 451 per degree of latitude, respectively). These slopes reflect a strong positive correlation between 452 the lightness of brown and cream areas, which is independent of the latitudinal trend $\left(\mathrm{R}^{2}=0.68\right.$; $453 \mathrm{p}<0.001$; Fig. 7). However, the relative proportion of the dorsal forewing surface that is brown 454 increases significantly with latitude $\left(\mathrm{R}^{2}=0.09, \mathrm{df}=702, \mathrm{p}<0.001\right)$. The analysis of contrast 455 (difference between cream and brown mean grey values) shows that the level of contrast 456 increases significantly with latitude (est. $=1.26 \pm 0.50, \mathrm{df}=46.37, \mathrm{t}=2.54$; Fig. 8), even when 457 accounting for population (England or Scotland) variation and collection date relative to the site458 specific emergence peak. 


\section{Discussion}

462 This study documents detailed wing morphological variation (size, shape and colour) in the

463 Speckled Wood butterfly, $P$. aegeria, across two recently expanded populations in mainland

464 Britain, suggesting differing responses to environmental and demographic factors. The size of $P$.

465 aegeria increases with latitude, consistent with Bergmann's rule, and during the range expansion

466 process, with more recently colonised populations being larger than core populations. Shape

467 changes, independent of size, are most strongly associated with colonisation history. Forewing

468 shape becomes more rounded, whereas hindwing shape becomes longer, in more recently

469 colonised populations and with latitude. The distribution of average lightness (opposite of

470 melanism) is more strongly associated with temperature during development than it is to latitude,

471 and runs contrary to the traditional thermal melanism hypothesis. Furthermore, the area of brown

472 relative to cream increases with latitude, but not enough to overcome the general lightening in

473 both areas. Finally, the contrast between brown and cream areas increases with latitude,

474 accounting for the human perception that individuals become darker further north. Overall, this

475 study sheds light on the interaction of temperature-sensitive plastic traits and selection during a

476 mainly climate-driven range expansion.

477

478 During range expansion, sections of a population experience different and new environmental

479 conditions that may result in local adaptation, be it through genetic changes or phenotypic

480 plasticity. Our analyses are of wild-caught individuals who experienced different environments

481 during development, making it impossible to separate plastic from genetic effects. Previous

482 broad sense heritability estimates in a $P$. aegeria population from southern Sweden $\left(h^{2}=0.38\right.$ -

483 0.45) indicate high potential for evolutionary responses in comparable morphological traits,

484 including wing size and colour pattern (Van Dyck \& Matthysen, 1998). Furthermore, a positive

485 correlation between thorax investment and wing shape, which was associated with acceleration

486 performance during take-off in males, had a heritability of 0.15 (Berwaerts, Matthysen \& Dyck,

487 2008). This heritability estimate is specific to acceleration performance, and so caution should be

488 taken if relating this to general dispersal ability. Thus, although we cannot quantify the effect of

489 developmental environment on our phenotypic distributions, there is likely to be a degree of

490 heritable genetic variance in all of our measured traits. 
492 Size and shape variation

493 Forewing and hindwing size in P. aegeria increases with colonisation and latitude. Larger

494 individuals were found in more recently colonised populations, following the expectation under

495 spatial selection if larger wings are associated with dispersal, for which there is some evidence

496 (Sekar, 2012; Flockhart et al., 2017). Our findings support the conclusion of Hughes et al.

497 (2003), which were based on thorax size across a much more limited number of sites and

498 geographic range of $P$. aegeria. On the reasonable assumption that wing size is directly

499 correlated to body size in this species, as in other Lepidoptera (Chai \& Srygley, 1990), increased

500 wing size with latitude follows Bergmann's rule, in agreement with previous studies (Dennis \&

501 Shreeve, 1989; Sibly, Winokur \& Smith, 1997). Temperature during development shows a

502 positive relationship with forewing size, which runs counter to the prediction of the temperature

503 size rule (Atkinson \& Sibly, 1997), but is consistent with experimental results (C. Macgregor,

504 unpub.). Within this underlying temperature-size relationship, there is also an additional effect of

505 season length and development time, as reflected by the observed reduction in size with number

506 of generations. A limitation of using ambient temperature as a measure of temperature during

507 development is that the micro-climate that individuals experience can be significantly modified

508 by behaviour and other environmental factors, such as humidity and sunlight. Under fast

509 demographic change, as in the range expansion of $P$. aegeria, the process of spatial selection

510 may override selection pressures from environmental gradients. For example, in the Scottish

511 expansion, wing size has responded more strongly to selection for dispersal than to the

512 environmental gradients (all recently colonised site are noticeably larger than the core

513 populations, irrespective of latitude and temperature).

514

515 The shape of forewings and hindwings, independent of size, were found to change during the

516 range expansion process and with increasing latitude. Forewings are more rounded and

517 hindwings are narrower in more recently colonised populations. Spatial selection during a range

518 expansion often results in increased dispersal ability towards the leading edge (Phillips, Brown \&

519 Shine, 2010). The finding that the number of years colonised has the strongest loading to shape

520 in both the forewings and hindwings suggests these shapes are more dispersive in this species.

521 However, interpreting the functional consequences of fine-scale wing shape variation for 
522 different dimensions of flight performance (e.g., dispersal efficiency, acceleration,

523 manoeuvrability) and tying shape changes to adaptive evolution is a complex and currently an

524 unresolved problem (Le Roy, Debat \& Llaurens, 2019). In fact, large, long and more pointed

525 forewings are often considered the most dispersive form as this is associated with (less

526 metabolically costly) gliding flight and migratory species, e.g. the Monarch butterfly (Danaus

527 plexippus; Altizer \& Davis, 2010; Flockhart et al., 2017). However, this assumption may not

528 hold true for all species. For example, in the Glanville Fritillary (Melitaea cinxia), dispersive

529 females have more rounded wings (Breuker, Brakefield \& Gibbs, 2007), whilst another study

530 found little or no evidence linking wing morphology to dispersal ability (Hanski et al., 2002).

531

532 In P. aegeria, the female is thought to be the more dispersive sex (Shreeve, 1986) and, in

533 general, is larger with more rounded wings compared to males (Pellegroms, Van Dongen \& Van

534 Dyck, 2009). Mate location strategy in male P. aegeria varies between two behaviours, perching

535 or patrolling, requiring different flight dynamics (Shreeve, 1984). Perchers require high

536 acceleration to defend a territorial sunlit patch and intercept passing females, whereas patrollers

537 require attributes for more sustained flight as they move from one spot to another in search of a

538 female. The differing flight requirements of these behaviours is reflected in their thorax size,

539 wing morphology and colour (Van Dyck, Matthysen \& Dhondt, 1997; Van Dyck \& Matthysen,

540 1998; Berwaerts, Van Dyck \& Aerts, 2002). An increase in forewing roundness was also found

541 in P. aegeria males across a large latitudinal $(700 \mathrm{~km})$ gradient from France to Netherlands,

542 where a decrease in aspect ratio (AR; calculated as $4 \mathrm{x}$ forewing length ${ }^{2} /$ forewing area), was

543 found further north (Vandewoestijne \& Van Dyck, 2011). The AR is widely used as a predictor

544 of flight performance but does not account for allometry, as in the geometric morphometric

545 approach used in this study. Therefore, comparisons between studies based on AR and this one

546 should be considered carefully. Nonetheless, Vandewoestijne and Van Dyck's finding supports

547 the pattern seen here, suggesting a common trend in wing shape with increasing latitude in this

548 species.

549

550 The majority of studies focus solely on forewing shape. Although butterflies are mostly

551 antermotoric (require, and predominantly use, forewings for flight), hindwings increase linear

552 and turning acceleration, so are particularly important for aerial agility and predator evasion 
553 (Jantzen \& Eisner, 2008). The distinct roles of wings in flight, coupled with our finding that

554 shape changes are different between forewings and hindwings, suggest that evolutionary factors

555 may differentially affect forewing and hindwing shape. This study highlights the need to include

556 both wings in future studies.

557

558 Colour and pattern variation

559 Pararge aegeria has been previously described as becoming darker further north in Britain

560 (Dennis \& Shreeve, 1989). However, using quantitative measurements and a more spatially

561 extensive sample, our results do not follow the expectation from the thermal melansim

562 hypothesis (i.e., decreasing lightness with latitude). Lightness fluctuates with latitude producing

563 a wave-like pattern that is consistent across both wings. The basal area becomes lighter with

564 latitude, whereas average lightness decreases with temperature during development (darker with

565 increasing temperature). Increased lightness at cooler temperatures during development could

566 support an energetic trade-off between overall growth and melanin production, which is costly to

567 synthesise (Talloen, Van Dyck \& Lens, 2004). The production of melanin may be subject to

568 selection pressures unrelated to thermoregulation (True, 2003). The level of melanism has

569 implications for disease resistance (Wilson et al., 2001; Dubovskiy et al., 2013) UV protection

570 (Bishop et al., 2016; Katoh, Tatsuta \& Tsuji, 2018), predation (Bond \& Kamil, 2002) and sexual

571 selection (Jiggins et al., 2001; Kemp, 2007). Our samples are of male individuals and so changes

572 in colour due to selection for thermoregulatory properties (increased melanism) are likely to be

573 constrained by sexual selection (Tuomaala, Kaitala \& Rutowski, 2012). Behavioural traits such

574 as posture during basking, which was not assessed in this study, also effect thermal regulation

575 (Kingsolver, 1985; Berwaerts et al., 2001). In P. aegeria, wing colour is associated with

576 alternative mate-location strategies, with perchers being lighter in colour than patrollers (Van

577 Dyck \& Matthysen, 1998). The sample used here is likely biased towards perchers due to the

578 increased likelihood of spotting and netting perching individuals. Furthermore, previous studies

579 that find decreased lightness with latitude also include thorax colour which was not possible in

580 this study (Zeuss et al., 2014).

581

582 The perceived darkening of $P$. aegeria at higher latitudes (as reported by recorders and the

583 authors of this study) is probably due to the relative changes of brown and cream areas on the 
584 forewing. The area of brown colour increases significantly with latitude, which may also have

585 thermal regulatory consequences. The strong correlation between the lightness of brown and

586 cream areas is indicative of an underlying genetic and developmental mechanism controlling the

587 'background' production of melanin across the whole wing surface that is also sensitive to

588 environmental cues during the larval or pupal stages. Nevertheless, the cream colour increases in

589 lightness significantly faster than the brown colour, resulting in an overall increase in contrast

590 between the brown and cream patches. Few studies have looked at the effect of pattern on

591 thermoregulation, but the wing band pattern in Banded Peacock (Anartia fatima) has been shown

592 to slow the rate of heating but not the overall thoracic temperature equilibrium (Brashears, Aiello

$593 \&$ Seymoure, 2016). The consequences of the specific traits detailed here on thermal properties

594 of $P$. aegeria wings have not been studied to date, and so conclusions relating these findings to

595 the thermal regulation should be made with care.

596

\section{Conclusion}

598 We have shown that the rapid expansion of P. aegeria across a temperature gradient in a

599 spatially fragmented landscape is associated with shifts in morphological traits that are

600 differentially affected by the environmental and demographic factors studied. Wing size and

601 shape are most strongly linked to latitude, following Bergmann's rule, and colonisation,

602 consistent with selection on dispersal. The spatial distribution of average lightness is only weakly

603 related to latitude and more associated with a plastic response to temperature during

604 development, which on the surface would appear to run contrary to the thermal melanism

605 hypothesis. Interpretation of the patterns observed here must take account of the dynamic nature

606 of this recent and ongoing range expansion. Populations are likely to be changing phenotypically

607 through adaptation to local environmental conditions and secondary immigration. Genetic drift

608 associated with colonisation, and evolutionary time-lags, may also account for some of the high

609 variance in phenotype-environment associations. The non-equilibrium state of many of the local

610 populations sampled, and an overriding role of selection for traits linked directly to range

611 expansion, may explain some of the weak phenotype-environment associations observed. The

612 planned application of genetic markers to this sample will help disentangle the roles of

613 developmental plasticity, selection, genetic drift and gene flow on these morphological traits.

614 


\section{Acknowledgements}

616 Distribution data was supplied by Butterflies for the New Millennium which is run by Butterfly 617 Conservation with funding from Natural England. We also thank Diana Taylor-Cox, Daniel 618 Egleston, Sean Clough, Romain Villoutreix, Duncan Lister, Alex Elsy, Georgina Palmer and 619 Melanie Smee for their help in sampling sites in the summers of 2016-2018, and Claire Williams 620 for dissecting and photographing individuals collected in 2016/17. Thank you to Carl Yung for 621 his advice and help with the field equipment. We thank Jon Bridle, Rus Hoelzel, Daniel Moore, 622 Konrad Lohse, Stuart Piertney, Mario Vallejo-Marin, Aimee Walker and Christine Balmer for 623 providing temporary space in their $-80^{\circ} \mathrm{C}$ freezers and liquid nitrogen to top up the dry shipper. 624 Finally, we thank Steven Van Belleghem for his help with Patternize and adapting the package 625 for our calibrations. 


\section{References}

629 Adams DC, Otárola-Castillo E. 2013. Geomorph : An R package for the collection and analysis 630 of geometric morphometric shape data. Methods in Ecology and Evolution 4:393-399. DOI: 10.1111/2041-210X.12035.

Altizer S, Davis AK. 2010. Populations of monarch butterflies with different migratory behaviours show divergence in wing morphology. Evolution 64:1018-1028. DOI: 10.1111/j.1558-5646.20.

Atkinson D. 1994. Temperature and organism size-A biological law for ectotherms? Advances

Atkinson D, Sibly RM. 1997. Why are organisms usually bigger in colder environments? Making sense of a life history puzzle. Trends in Ecology and Evolution 12:235-239. DOI: 10.1016/S0169-5347(97)01058-6.

Baayen RH, Davidson DJ, Bates DM. 2008. Mixed-effects modeling with crossed random effects for subjects and items. Journal of Memory and Language 59:390-412. DOI: 10.1016/j.jml.2007.12.005.

Bates D, Mächler M, Bolker BM, Walker SC. 2015. Fitting linear mixed-effects models using lme4. Journal of Statistical Software:1-48. DOI: 10.18637/jss.v067.i01.

Bergmann C. 1848. Über die verhältnisse der wärmeökonomie der thiere zu ihrer größe. Göttingen 1:595-708.

Berwaerts K, Van Dyck H, Aerts P. 2002. Does flight morphology relate to flight performance? An experimental test with the butterfly Pararge aegeria. Functional Ecology 16:484-491. DOI: 10.1046/j.1365-2435.2002.00650.x.

Berwaerts K, Van Dyck H, Vints E, Matthysen E. 2001. Effect of manipulated wing characteristics and basking posture on thermal properties of the butterfly Pararge aegeria (L .). Journal of Zoology 255:261-267. DOI: 10.1017/S0952836901001327.

Berwaerts K, Matthysen E, Dyck H Van. 2008. Take-off flight performance in the butterfly Pararge aegeria relative to sex and morphology: A quantitative genetic assessment. Evolution 62:2525-2533. DOI: 10.1111/j.1558-5646.2008.00456.x.

Betts BYCR, Wootton RJ. 1988. Wing shape and flight behaviour in butterflies (Lepidoptera: Papilionoidea and Hesperioidea): A preliminary analysis. Journal of Experimental Biology 
658

659

660

661

662

663

664

665

666

667

668

669

670

671

672

673

674

675

676

677

678

679

680

681

682

683

684

685

686

687

688

138:271-288.

Bishop TR, Robertson MP, Gibb H, van Rensburg BJ, Braschler B, Chown SL, Foord SH, Munyai TC, Okey I, Tshivhandekano PG, Werenkraut V, Parr CL. 2016. Ant assemblages have darker and larger members in cold environments. Global Ecology and Biogeography 25:1489-1499. DOI: 10.1111/geb.12516.

Blanckenhorn WU, Demont M. 2004. Bergmann and converse bergmann latitudinal clines in arthropods: Two ends of a continuum? Integrative and Comparative Biology 44:413-424. DOI: $10.1093 / \mathrm{icb} / 44.6 .413$.

Bond AB, Kamil AC. 2002. Visual predators select for crypticity and polymorphism in virtual prey. Nature 415:609-613. DOI: 10.1038/415609a.

Brashears J, Aiello A, Seymoure BM. 2016. Cool Bands : Wing bands decrease rate of heating, but not equilibrium temperature in Anartia fatima. Journal of Thermal Biology 56:100-108. DOI: $10.1016 /$ j.jtherbio.2016.01.007.

Breuker CJ, Brakefield PM, Gibbs M. 2007. The association between wing morphology and dispersal is sex-specific in the Glanville fritillary butterfly Melitaea cinxia (Lepidoptera : Nymphalidae). European Journal of Entomology 104:445-452. DOI: 10.14411/eje.2007.064.

Burton OJ, Travis JMJ. 2008. The frequency of fitness peak shifts is increased at expanding range margins due to mutation surfing. Genetics 179:941-950. DOI: 10.1534/genetics.108.087890.

Chai P, Srygley RB. 1990. Predation and the flight, morphology, and temperature of neotropical rain-forest butterflies. The American NaturalistAmerican Naturalist 135:748-765. DOI: $10.1086 / 285072$.

Chown SL, Gaston KJ. 2010. Body size variation in insects: A macroecological perspective. Biological Reviews 85:139-169. DOI: 10.1111/j.1469-185X.2009.00097.x.

Clusella Trullas S, van Wyk JH, Spotila JR. 2007. Thermal melanism in ectotherms. Journal of Thermal Biology 32:235-245. DOI: 10.1016/j.jtherbio.2007.01.013.

Curth S, Fischer MS, Kupczik K. 2017. Can skull form predict the shape of the temporomandibular joint? A study using geometric morphometrics on the skulls of wolves and domestic dogs. Annals of Anatomy 214:53-62. DOI: 10.1016/j.aanat.2017.08.003.

Daufresne M, Lengfellner K, Sommer U. 2009. Global warming benefits the small in aquatic 
689

690

691

692

693

694

695

696

697

698

699

700

701

702

703

704

705

706

707

708

709

710

711

712

713

714

715

716

717

718

719

ecosystems. Proceedings of the National Academy of Sciences of the United States of America 106:12788-12793. DOI: 10.1073/pnas.0902080106.

Dennis RLH, Shreeve TG. 1989. Butterfly wing morphology variation in the British Isles: the influence of climate, behavioural posture and the hostplant-habitat. Biological Journal of the Linnean Society 38:323-348. DOI: 10.1111/j.1095-8312.1989.tb01581.x.

Dubovskiy IM, Whitten MMA, Kryukov VY, Yaroslavtseva ON, Grizanova E V., Greig C, Mukherjee K, Vilcinskas A, Mitkovets P V., Glupov V V., Butt TM. 2013. More than a colour change: Insect melanism, disease resistance and fecundity. Proceedings of the Royal Society B: Biological Sciences 280:20130584. DOI: 10.1098/rspb.2013.0584.

Emmet A., Heath J. 1990. The Butterflies of Great Britain and Ireland. Colchester: Harley Books.

Flockhart DTT, Fitz-gerald B, Brower LP, Derbyshire R, Altizer S, Hobson KA, Wassenaar LI, Norris DR. 2017. Migration distance as a selective episode for wing morphology in a migratory insect. Movement Ecology 5:1-9. DOI: 10.1186/s40462-017-0098-9.

Hanski I, Breuker CJ, Schops K, Setchfield R, Nieminen M. 2002. Population history and life history influence the migration rate of female Glanville fritillary butterflies. Oikos 98:8797. DOI: 10.1034/j.1600-0706.2002.980109.x.

Heidrich L, Friess N, Fiedler K, Brändle M, Hausmann A, Brandl R, Zeuss D. 2018. The dark side of Lepidoptera: Colour lightness of geometrid moths decreases with increasing latitude. Global Ecology and Biogeography 27:407-416. DOI: 10.1111/geb.12703.

Hickling R, Roy DB, Hill JK, Fox R, Thomas CD. 2006. The distributions of a wide range of taxonomic groups are expanding polewards. Global Change Biology 12:450-455. DOI: 10.1111/j.1365-2486.2006.01116.x.

Hill JK, Griffiths HM, Thomas CD. 2011. Climate change and evolutionary adaptations at species' range margins. Annual Review of Entomology 56:143-159. DOI: 10.1146/annurevento-120709-144746.

Hill JK, Thomas CD, Huntley B. 1999. Climate and habitat availability determine 20th century changes in a butterfly's range margin. Proceedings of the Royal Society B: Biological Sciences 266:1197-1206. DOI: 10.1098/rspb.1999.0763.

Hill JK, Thomas CD, Lewis OT. 1999. Flight morphology in fragmented populations of a rare British butterfly, Hesperia comma. Biological Conservation 87:277-283. 
720 Horne CR, Hirst AG, Atkinson D. 2015. Temperature-size responses match latitudinal-size

721 clines in arthropods, revealing critical differences between aquatic and terrestrial species.

722 Ecology Letters 18:327-335. DOI: 10.1111/ele.12413.

723 Hughes CL, Hill JK, Dytham C. 2003. Evolutionary trade-offs between reproduction and

724 dispersal in populations at expanding range boundaries. Proceedings of the Royal Society B:

725 Biological Sciences 270:S147-S150. DOI: 10.1098/rsbl.2003.0049.

726 Jantzen B, Eisner T. 2008. Hindwings are unnecessary for flight but essential for execution of

727 normal evasive flight in Lepidoptera. Proceedings of the National Academy of Sciences

728 105:16636-16640. DOI: 10.1073/pnas.0807223105.

729

Jiggins C, Naisbit R., Coe R., Mallet J. 2001. Premating isolation caused by colour pattern mimicry. Nature 411:302-305. DOI: 10.1038/35077075.

731

Katoh M, Tatsuta H, Tsuji K. 2018. Ultraviolet exposure has an epigenetic effect on a Batesian

732

733 mimetic trait in the butterfly Papilio polytes. Scientific Reports 8:13416. DOI:

734 10.1038/s41598-018-31732-8.

Kemp DJ. 2007. Female butterflies prefer males bearing bright iridescent ornamentation. 10.1098/rspb.2006.0043.

Kingsolver JG. 1985. Thermoregulatory significance of wing melanisation in Pieris butterflies 10.1007/BF00379348.

Kingsolver JG. 1995. Viability selection on seasonally polyphenic traits: Wing melanin pattern in western white butterflies. Evolution 49:932. DOI: 10.2307/2410415.

Kingsolver JG, Massie KR, Ragland GJ, Smith MH. 2007. Rapid population divergence in thermal reaction norms for an invading species : breaking the temperature - size rule. Journal of Evolutionary Biology 20:892-900. DOI: 10.1111/j.1420-9101.2007.01318.x.

Klingenberg CP. 2009. Morphometric integration and modularity in configurations of landmarks : tools for evaluating a priori hypotheses. Evolution and Development 11:405421. DOI: $10.1111 / \mathrm{j} .1525-142 X .2009 .00347 . x$.

Klingenberg CP. 2011. MorphoJ : an integrated software package for geometric morphometrics. Molecular Ecology Resources 11:353-357. DOI: 10.1111/j.1755-0998.2010.02924.x. 
751

752

753

754

755

756

757

758

759

760

761

762

763

764

765

766

767

768

769

770

771

772

773

774

775

776

777

778

779

780

781

Research Methods 49:1494-1502. DOI: 10.3758/s13428-016-0809-y.

Macgregor CJ, Thomas CD, Roy DB, Beaumont MA, Bell JR, Brereton T, Bridle JR, Dytham C, Fox R, Gotthard K, Hoffmann AA, Martin G, Middlebrook I, Nylin S, Platts PJ, Rasteiro R, Saccheri IJ, Villoutreix R, Wheat CW, Hill JK. 2019. Climate-induced phenology shifts linked to range expansions in species with multiple reproductive cycles per year. Nature Communications 10:4455. DOI: 10.1038/s41467-019-12479-w.

Mattila ALK. 2015. Thermal biology of flight in a butterfly: Genotype, flight metabolism, and environmental conditions. Ecology and Evolution 5:5539-5551. DOI: 10.1002/ece3.1758.

Merckx T, Van Dyck H. 2006. Landscape structure and phenotypic plasticity in flight morphology in the butterfly Pararge aegeria. Oikos 113:226-232. DOI: 10.1111/j.2006.0030-1299.14501.x.

Mousseau TA. 2006. Ectotherms follow the converse to Bergmann's rule. Evolution 51:630-632. DOI: $10.2307 / 2411138$.

Niitepõld K, Smith AD, Osborne JL, Reynolds DR, Carreck NL, Martin AP, Marden JH, Ovaskainen O, Hanski I. 2009. Flight metabolic rate and Pgi genotype influence butterfly dispersal rate in the field. Ecology 90:2223-2232. DOI: 10.1890/08-1498.1.

Nylin S, Svärd L. 1991. Latitudinal patterns in the size of European butterflies. Holarctic Ecology 14:192-202. DOI: 10.1111/j.1600-0587.1991.tb00652.x.

Parmesan C. 2006. Ecological and evolutionary responses to recent climate change. Annual Review of Ecology, Evolution, and Systematics 37:637-669. DOI: 10.2307/annurev.ecolsys.37.091305.30000024.

Parmesan C, Ryrholm N, Stefanescu C, Hill JK, Thomas CD, Descimon H, Huntley B, Kaila L, Kullberg J, Tammaru T, Tennent WJ, Thomas JA, Warren M. 1999. Poleward shifts in geographical ranges of butterfly species associated with regional warming. Nature 399:579583. DOI: $10.1038 / 21181$.

Parmesan C, Yohe G. 2003. A globally coherent fingerprint of climate change impacts across natural systems. Nature 421:37-42. DOI: 10.1038/nature01286.

Pellegroms B, Van Dongen S, Van Dyck H. 2009. Larval food stress differentially affects flight morphology in male and female speckled woods (Pararge aegeria). Ecological Entomology 34:387-393. DOI: 10.1111/j.1365-2311.2009.01090.x.

Phillips S, Anderson R, Schapire R. 2006. Maximum entropy modeling of species geographic 
782

783

784

785

786

787

788

789

790

791

792

793

794

795

796

797

798

799

800

801

802

803

804

805

806

807

808

809

810

811

812

distributions. Ecological Modelling 190:231-259. DOI: 10.1016/j.ecolmodel.2005.03.026.

Phillips BL, Brown G., Shine R. 2010. Life-history evolution in range-shifting populations. Ecology 91:1617-1627. DOI: 10.1002/ecm.1242.

Pujol B, Blanchet S, Charmantier A, Danchin E, Facon B, Marrot P, Roux F, Scotti I, Teplitsky C, Thomson CE, Winney I. 2018. The missing response to selection in the wild. Trends in Ecology and Evolution 33:337-346. DOI: 10.1016/j.tree.2018.02.007.

Renault D. 2020. A review of the phenotypic traits associated with insect dispersal polymorphism, and experimental designs for sorting out resident and disperser phenotypes. Insects 11:1-26. DOI: 10.3390/insects11040214.

Roff DA. 1980. Optimizing development time in a seasonal environment : The "ups and downs" of clinal variation. International Association for Ecology 45:202-208. DOI: 10.1007/BF00346461.

Rohlf FJ. 2017. tpsDig2, digitize landmarks and outlines, version 2.31. Department of Ecology and Evolution, State University of New York at Stony Brook.

Rohlf FJ. 2019. tpsUtil, file utility program, version 1.78. Department of Ecology and Evolution, State University of New York at Stony Brook.

Rohlf FJ, Corti M. 2000. Use of two-block partial least-squares to study covariation in shape. Systematic biology 49:740-753. DOI: 10.1080/106351500750049806.

Rohlf FJ, Slice D. 1990. Extensions of the Procrustes method for the optimal superimposition of landmarks. Systematic Zoology 39:40-59. DOI: 10.2307/2992207.

Roskam JC, Brakefield PM. 1999. Seasonal polyphenism in Bicyclus (Lepidoptera: Satyridae) butterflies: Different climates need different cues. Biological Journal of the Linnean Society 66:345-356. DOI: 10.1006/bij1.1998.0268.

Le Roy C, Debat V, Llaurens V. 2019. Adaptive evolution of butterfly wing shape: from morphology to behaviour. Biological Reviews 94:1261-1281. DOI: 10.1111/brv.12500.

Sekar S. 2012. A meta-analysis of the traits affecting dispersal ability in butterflies : can wingspan be used as a proxy? Journal of Animal Ecology 81:174-184. DOI: 10.1111/j.1365-2656.2011.01909.x.

Shelomi M. 2012. Where are we now? Bergmann's rule Sensu Lato in insects. American Naturalist 180:511-519. DOI: 10.1086/667595.

Shreeve TG. 1984. Habitat selection, mate location, and microclimate constraints on the activity 
813 of the speckled wood butterfly Pararge aegeria. Oikos 42:371-377. DOI: 10.2307/3544407.

814 Shreeve TG. 1986. Egg-laying by the speckled wood butterfly (Pararge aegeria): the role of

815 female behaviour, host plant abundance and temperature. Ecological Entomology 11:229-

816 236. DOI: $10.1111 /$ j.1365-2311.1986.tb00298.x.

817 Sibly RM, Winokur L, Smith RH. 1997. Interpopulation variation in phenotypic plasticity in the 818 Speckled Wood butterfly, Pararge aegeria. Oikos 78:323-330. DOI: 10.2307/3546300.

819 Simmons AD, Thomas CD. 2004. Changes in dispersal during species' range expansions. The $820 \quad$ American Naturalist 164:378-395. DOI: 10.1086/423430.

821 Srygley RB, Chai P. 1990. Flight morphology of Neotropical butterflies: palatability and

822 distribution of mass to the thorax and abdomen. Oecologia 84:491-499. DOI:

$823 \quad 10.1007 / \mathrm{BF} 00328165$.

824 Stillwell RC, Moya-lara J, Fox CW. 2008. Selection does not favor larger body size at lower

825 temperature in a seed-feeding beetle. Evolution 62:2534-2544. DOI: $10.1111 / \mathrm{j} .1558$ -

$826 \quad 5646.2008 .00467 . x$.

827 Talloen W, Van Dyck H, Lens L. 2004. The cost of melanization: butterfly wing coloration

828 under environmental stress. Evolution 58:360-366. DOI: 10.1554/03-250.

829 Thomas CD, Bodsworth EJ, Wilson RJ, Simmons AD, Davies ZG, Conradt L. 2001. Ecological

830 and evolutionary processes at expanding range margins. Nature 411:577-581. DOI:

$831 \quad 10.1038 / 35079066$.

832 True JR. 2003. Insect melanism: The molecules matter. Trends in Ecology and Evolution 833 18:640-647. DOI: 10.1016/j.tree.2003.09.006.

834 Tuomaala M, Kaitala A, Rutowski RL. 2012. Females show greater changes in wing colour with 835 latitude than males in the green-veined white butterfly, Pieris napi (Lepidoptera: Pieridae). 836 Biological Journal of the Linnean Society 107:899-909. DOI: 10.1111/j.1095837 8312.2012.01996.x.

838 Van Belleghem SM, Papa R, Ortiz-Zuazaga H, Hendrickx F, Jiggins CD, McMillan WO, 839 Counterman BA. 2018. Patternize : An R package for quantifying colour pattern variation. $840 \quad$ Methods in Ecology and Evolution 9:390-398. DOI: 10.1111/2041-210X.12853.

841 Vandewoestijne S, van Dyck H. 2010. Population genetic differences along a latitudinal cline 842 between original and recently colonized habitat in a butterfly. PLoS ONE 5:e13810. DOI: $843 \quad$ 10.1371/journal.pone.0013810. 
844 Vandewoestijne S, Van Dyck H. 2011. Flight morphology along a latitudinal gradient in a

845 butterfly: Do geographic clines differ between agricultural and woodland landscapes?

846 Ecography 34:876-886. DOI: 10.1111/j.1600-0587.2010.06458.x.

847 van Heteren AH, Maclarnon A, Soligo C, Rae TC. 2016. Functional morphology of the cave bear

848 (Ursus spelaeus) mandible: A 3D geometric morphometric analysis. Organisms Diversity

849 and Evolution 16:299-314. DOI: 10.1007/s13127-015-0238-2.

850 Van Dyck H, Matthysen E. 1998. Thermoregulatory differences between phenotypes in the

851 speckled wood butterfly: Hot perchers and cold patrollers? Oecologia 114:326-334. DOI:

$852 \quad 10.1007 / \mathrm{s} 004420050454$.

853 Van Dyck H, Matthysen E, Dhondt AA. 1997. The effect of wing colour on male behavioural

854 strategies in the speckled wood butterfly. Animal Behaviour 53:39-51. DOI:

$855 \quad 10.1006 /$ anbe.1996.0276.

856 Van Dyck H, Wiklund C. 2002. Seasonal butterfly design: Morphological plasticity among three developmental pathways relative to sex, flight and thermoregulation. Journal of

859 Evolutionary Biology 15:216-225. DOI: 10.1046/j.1420-9101.2002.00384.x.

Warren M, Hill J, Thomas J, Asher J, Fox R, Huntley B, Roy D., Telfer M, Jeffcoate S, Harding 860

861

862 P, Jeffcoate G, Wills S, Greatorez-Davies J, Moss D, Thomas C. 2001. Rapid responses of

863 British butterflies to opposing forces of climate and habitat change. Nature 414:65-69.

Wood SN. 2004. Stable and Efficient Multiple Smoothing Parameter Estimation for Generalized Additive Models. Journal of the American Statistical Association 99:673-686. DOI: 10.1198/016214504000000980.

872 DOI: $10.1038 / 35102054$.

Wasserthal LT. 1975. The rôle of butterfly wings in regulation of body temperature. Journal of Insect Physiology 21:1921-1930. DOI: 10.1016/0022-1910(75)90224-3.

Wickham H. 2016. ggplot2: Elegant graphics for data analysis. Springer-Verlag New York.

Wilson K, Cotter SC, Reeson AF, Pell JK. 2001. Melanism and disease resistance in insects. Ecology Letters 4:637-649. DOI: 10.1046/j.1461-0248.2001.00279.x.

Zeuss D, Brandl R, Brändle M, Rahbek C, Brunzel S. 2014. Global warming favours lightcoloured insects in Europe. Nature Communications 5:3874. DOI: 10.1038/ncomms4874.

Zeuss D, Brunzel S, Brandl R. 2017. Environmental drivers of voltinism and body size in insect assemblages across Europe. Global Ecology and Biogeography 26:154-165. DOI: 
$875 \quad 10.1111 /$ geb. 12525 . 


\section{Figure 1}

Sample sites and expansion of Pararge aegeria from 1965-2017 with confidence of colonisation year.

The map shows the distribution of $P$. aegeria and the pattern of range expansion from 1965-2017. Colours show years when $P$. aegeria was first recorded at a $10 \mathrm{~km}$ grid resolution. Crosses indicate site locations sampled for the study (Table S1 for details). The shape of each $10 \mathrm{~km}$ grid shows the confidence of the colonisation year record: grids colonised pre-1975 are considered core (squares); grids colonised after three or more well-recorded years (as defined by species richness records) are considered high confidence colonisations (filled circles); grids where the colonisation record is before the third year of good records are considered uncertain colonisations (unfilled circles). Two expansions have taken place, one from south-western England and the second from a refuge population in western Scotland. Map is from Google Static Maps API and plotted with ggmap in R (Kahle \& Wickham, 2013). 


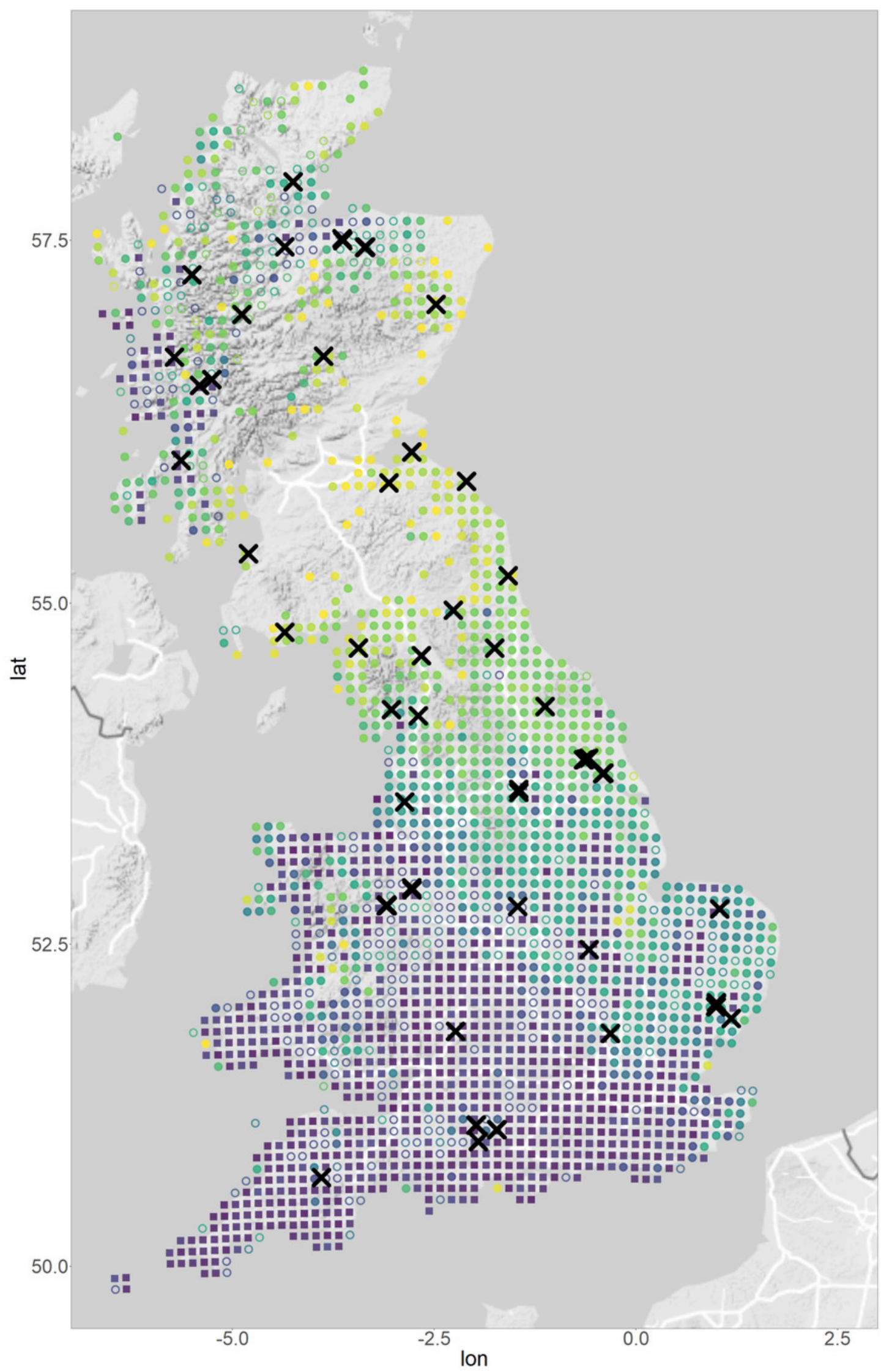

First record

2010

2000

1990

1980

1970

Colonisation confidence

- Core

- High

- Low 
Figure 2

Pararge aegeria photographic set-up and landmarks.

Example image of dissected $P$. aegeria wings with the ColorGauge Micro Target (A). Forewing (B) and hindwing (C) landmarks. Each landmark was placed at either a vein-vein or vein-wing margin intersection. 
A
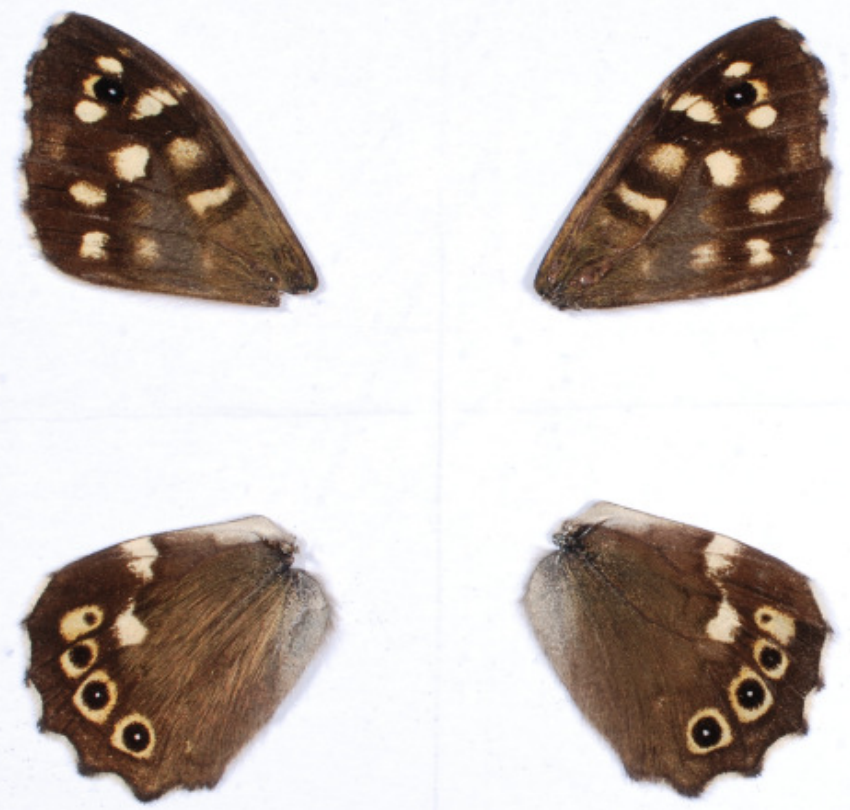

Pararge aegeria Migdale Wood; NH69

PA-S-32-MW-2018-13

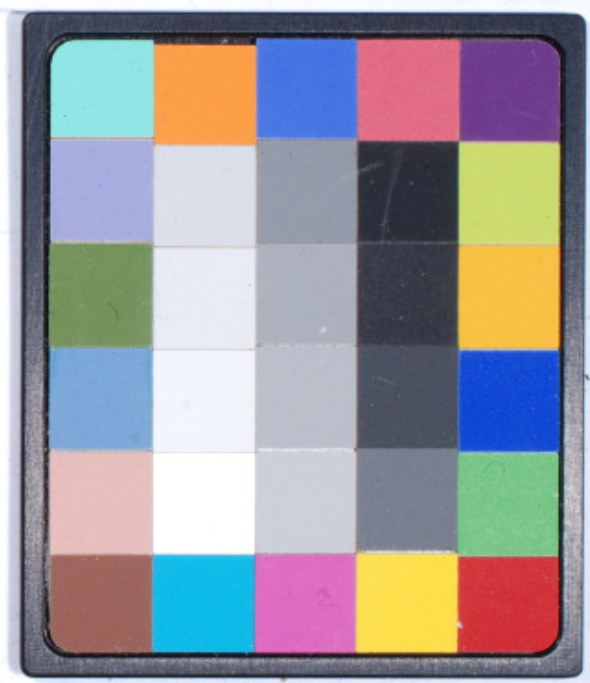

B

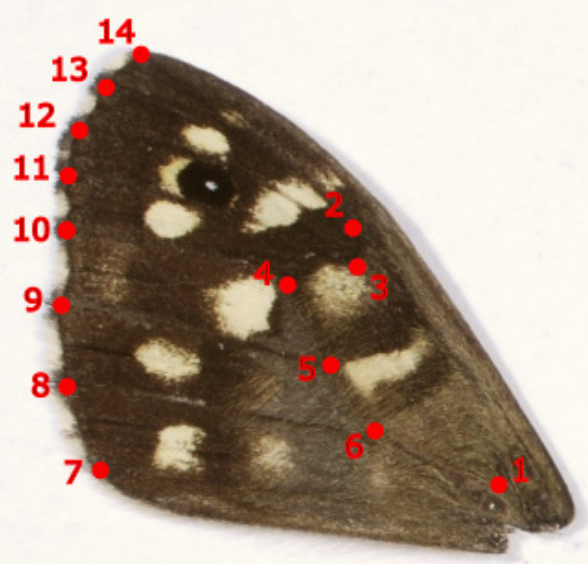

C

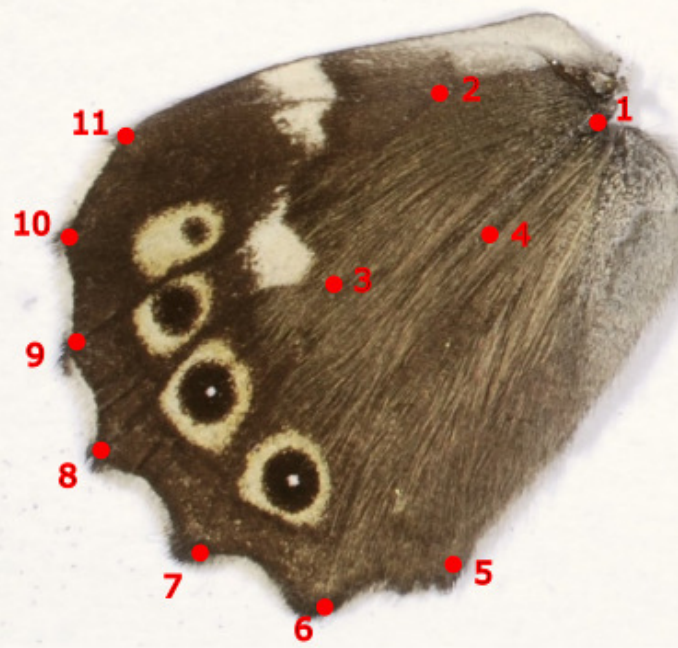




\section{Figure 3}

Effect of environmental variables on forewing and hindwing size (centroid size).

Linear mixed model estimated of the effect, shown as probability distributions, of four environmental variables on forewing (blue) and hindwing (orange) centroid size of $P$. aegeria.

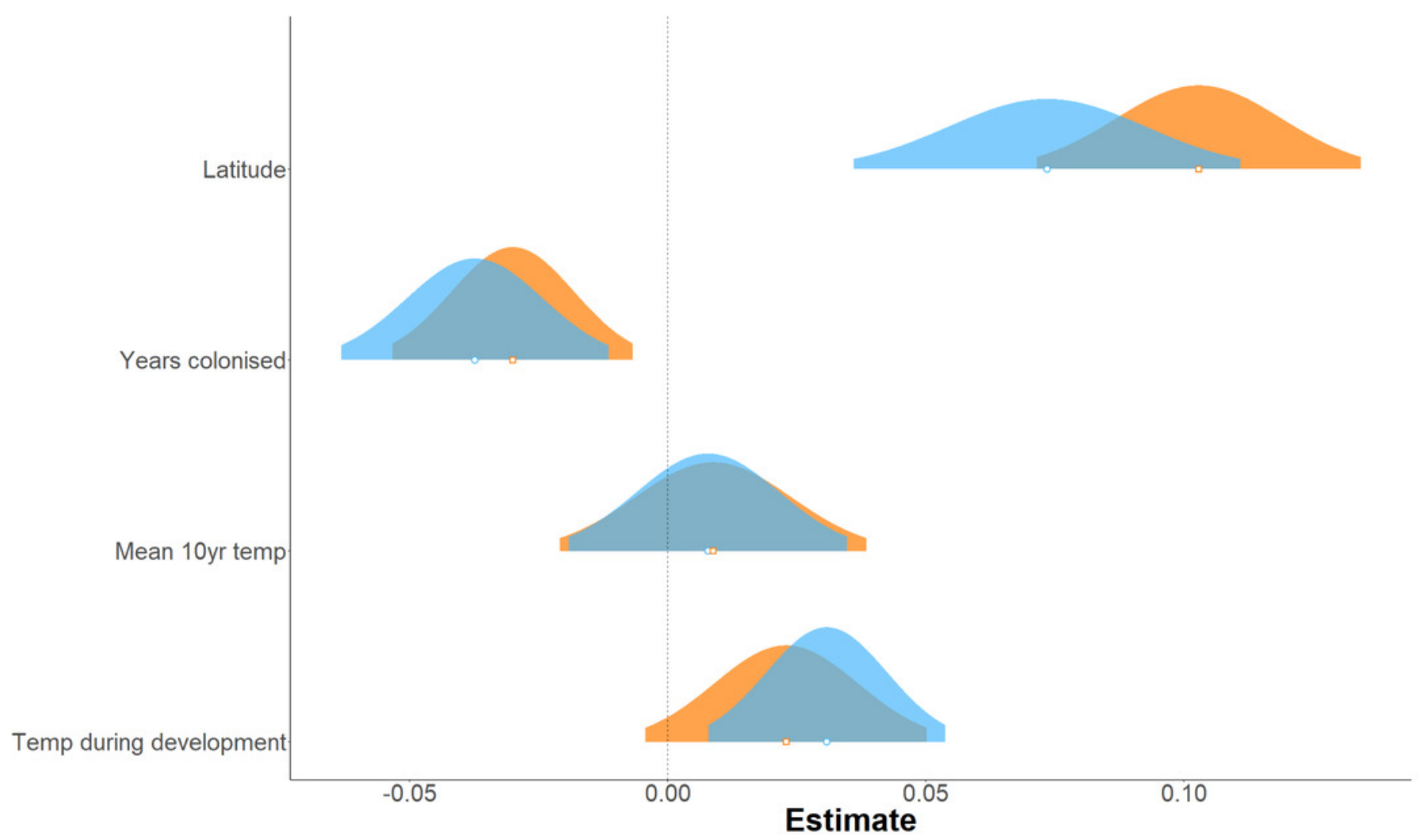


Figure 4

Pararge aegeria wing allometry.

Regression (solid line with standard error in grey) of the wing shape variable on forewing (A) and hindwing (B) size (log centroid size, CS) in Pararge aegeria. Data are separated into the two regional populations (England=purple circles; Scotland= yellow triangles). Shape changes associated with different values of log CS are shown using a wireframe diagram for forewings ( $\mathbf{C}$ and $\mathbf{D}$ ) and hindwings ( $\mathbf{E}$ and $\mathbf{F}$ ). The blue wireframe is the consensus (or average) shape of all the individuals, whilst the orange indicates the shape at each log CS as indicated.

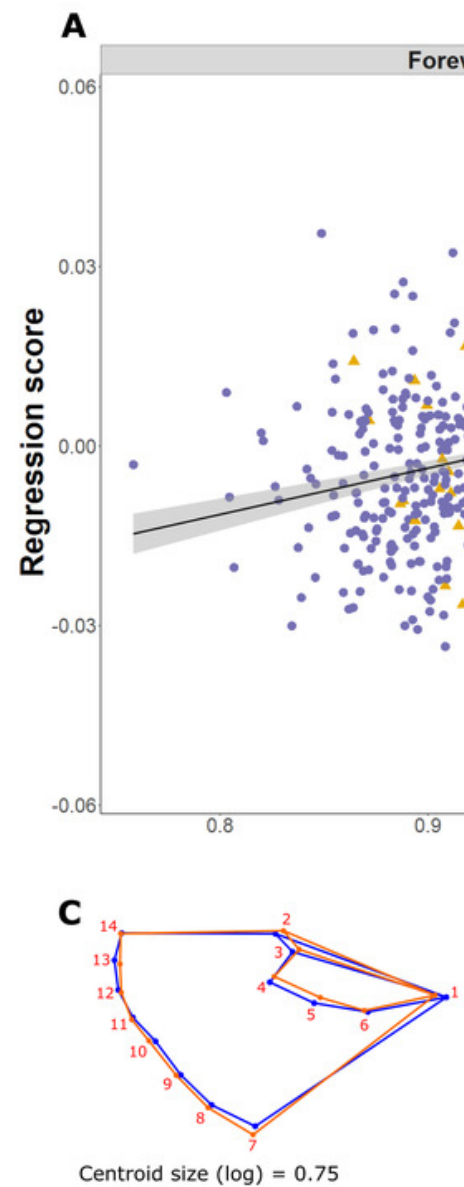

Centroid size $(\log )=0.75$
D

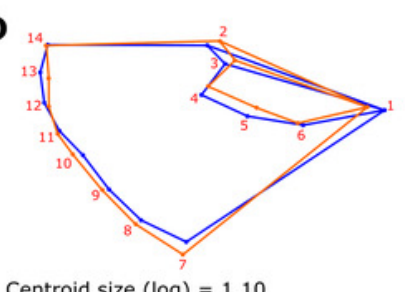

Centroid size $(\log )=1.10$
B
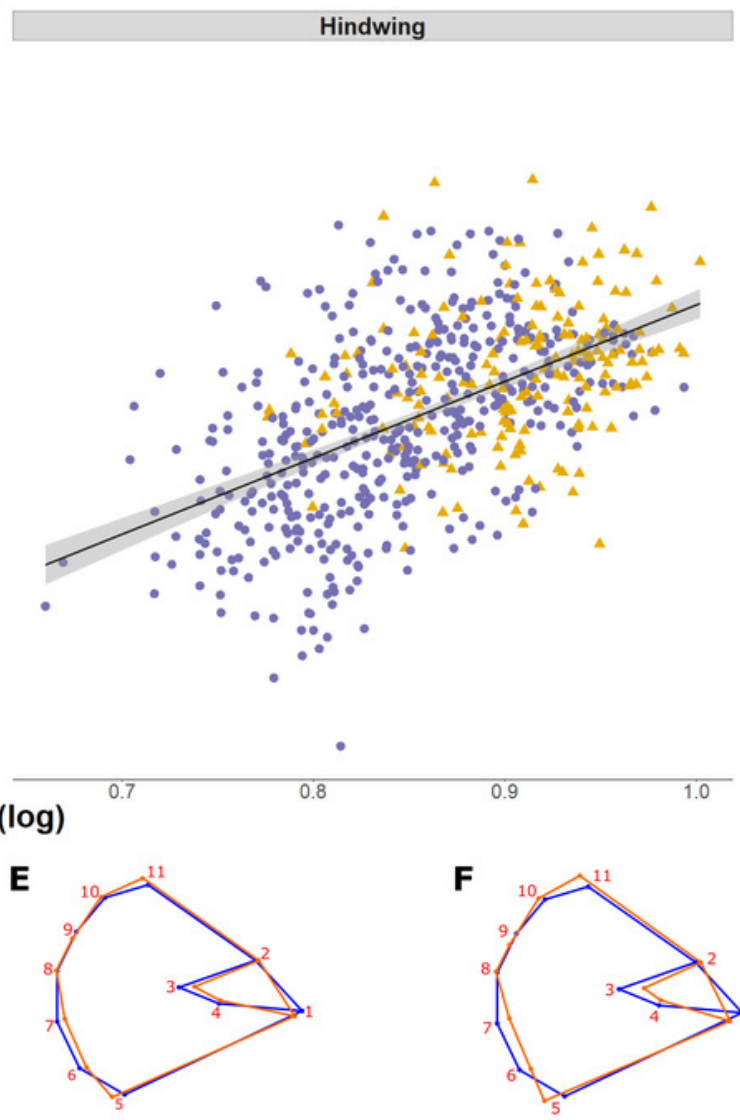

Centroid size $(\log )=0.65$

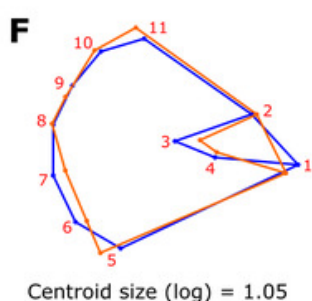




\section{Figure 5}

Two-block partial least squares (2B-PLS) axis 1 shape changes for forewing and hindwing.

The plot shows PLS1 axis for block 1 (i.e., size-adjusted shape variable) against PLS1 axis for block 2 (environmental variables) for forewing (A) and hindwing (B). The points are coloured according to which expansion they originate (England= purple circles; Scotland= yellow triangles). The change of shape associated across the PLS1 axis is shown using wireframe plots, where the blue line is the consensus shape (or average) and orange is the shape present at the axis value of -0.1 (C and $\mathbf{E}$ ) and 0.1 ( $\mathbf{D}$ and $\mathbf{F}$ ) for forewing and hindwings respectively. 
A

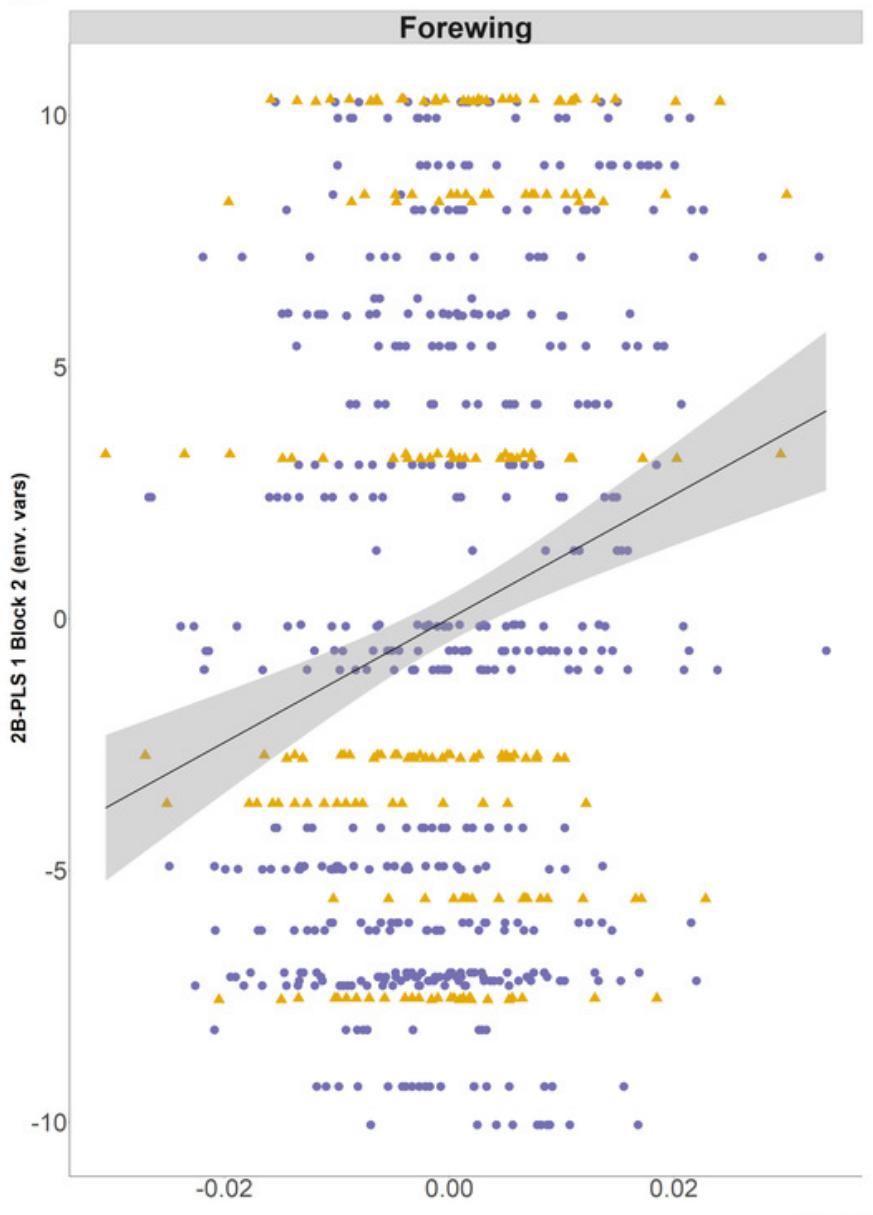

B

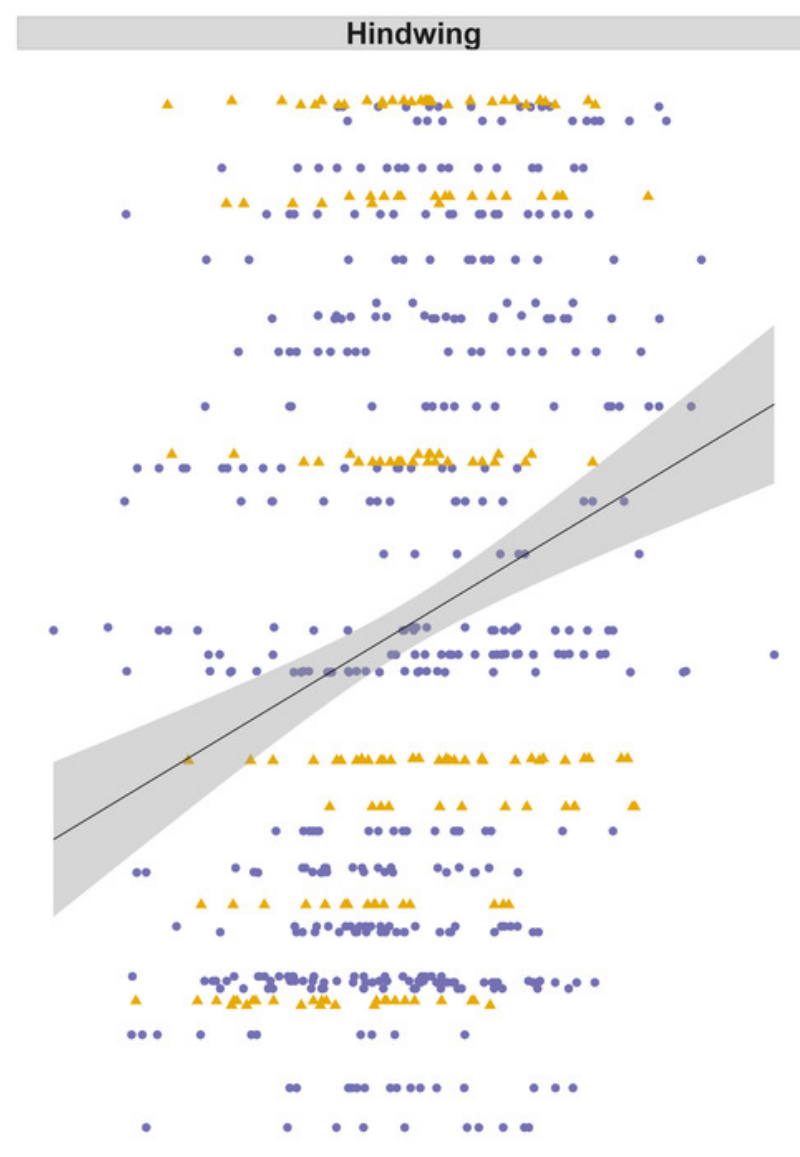

2B-PLS 1 Block 1 (shape)

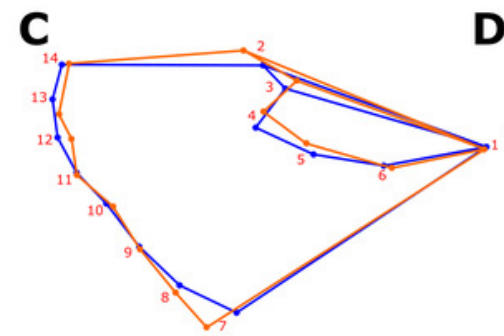

D
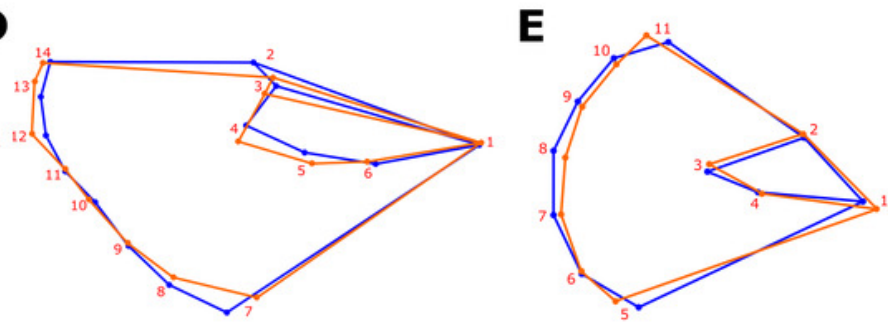

F

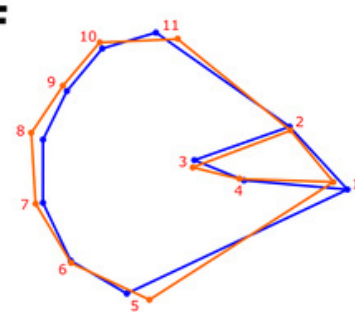


Figure 6

Forewing and hindwing whole wing dorsal lightness with latitude.

The forewing (A) and hindwing (B) dorsal lightness (mean grey value) relationship with latitude. A mean grey value of 255 is white and 0 is black. Populations are coloured according to England (purple) or Scotland (yellow) expansion.

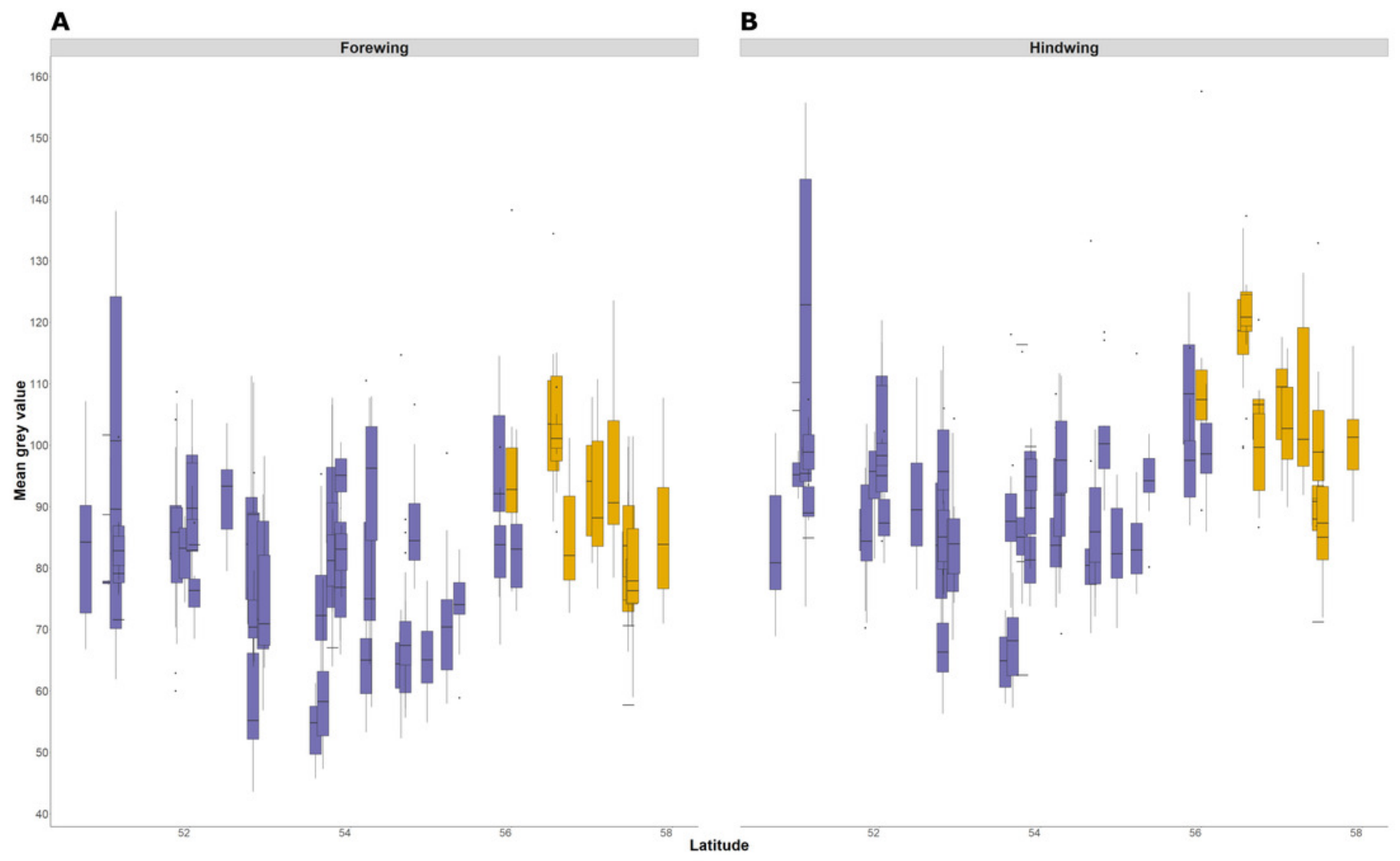




\section{Figure 7}

Forewing brown and cream lightness correlation independent of latitude.

There is a strong correlation of brown and cream lightness (mean grey value), even when accounting for latitude. Example wings are inserted to demonstrate the colour change occurring across the regression. 


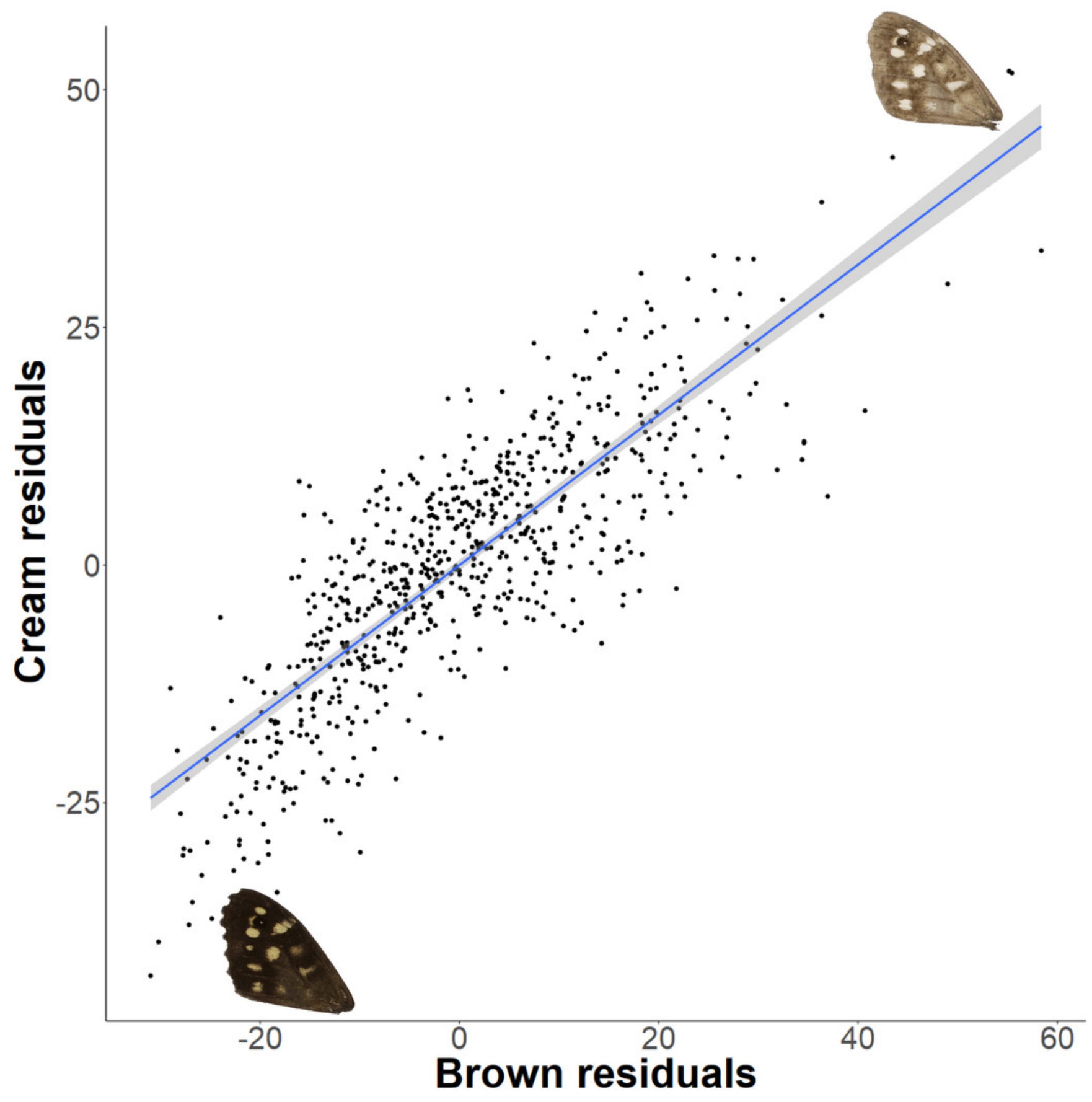


Figure 8

Effect of latitude on contrast between brown and cream areas.

The relationship between contrast (difference between mean grey values of the cream and brown areas) on the dorsal forewing surface and latitude. The points are coloured according to which expansion they originate (England= purple circles; Scotland= yellow triangles). Example wings are inserted to demonstrate the colour change occurring at contrasting ends of the relationship. 


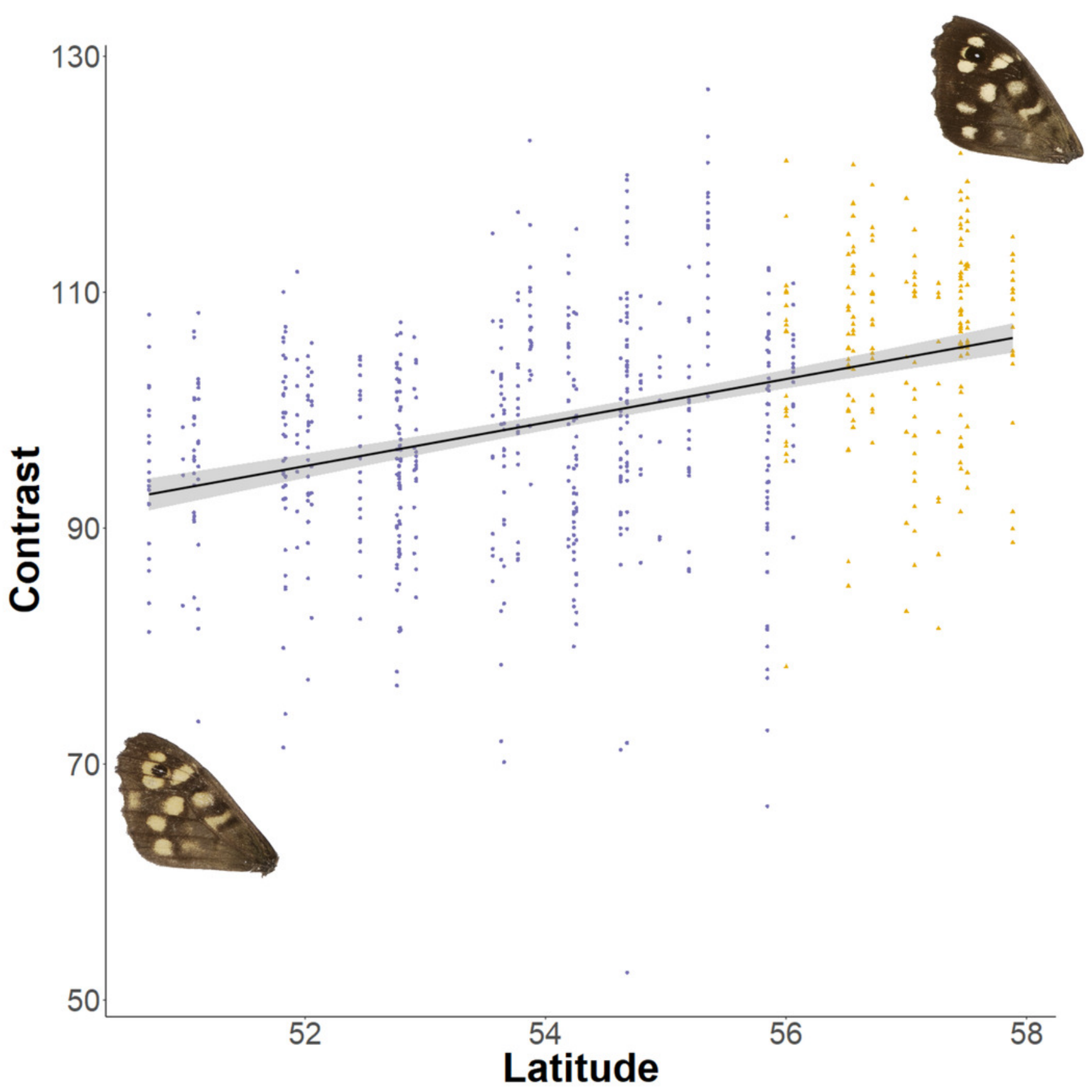




\section{Table $\mathbf{1}$ (on next page)}

Linear mixed model results for forewing and hindwing size (centroid size). 


\begin{tabular}{|c|c|c|c|c|c|c|c|c|}
\hline \multirow[b]{2}{*}{ Predictors } & \multicolumn{4}{|c|}{ Forewing centroid size } & \multicolumn{4}{|c|}{ Hindwing centroid size } \\
\hline & Est. & $S E$ & $d f$ & $t$ & Est. & SE & $d f$ & $t$ \\
\hline (Intercept) & 0.31 & 0.56 & 20.44 & 0.55 & -0.69 & 0.54 & 1.62 & -1.28 \\
\hline Latitude & 0.04 & 0.01 & 13.31 & 3.85 & 0.05 & 0.01 & 0.48 & 6.43 \\
\hline Years colonised & -0.002 & 0.001 & 15.09 & -2.83 & -0.002 & 0.00 & 0.77 & -2.53 \\
\hline $\begin{array}{l}\text { Mean 10yr } \\
\text { annual temp }\left(T_{10}\right)\end{array}$ & 0.01 & 0.02 & 40.83 & 0.57 & 0.012 & 0.02 & 28.63 & 0.58 \\
\hline $\begin{array}{l}\text { Temp. during } \\
\text { development }\end{array}$ & 0.02 & 0.01 & 31.30 & 2.64 & 0.02 & 0.01 & 33.83 & 1.65 \\
\hline \multicolumn{9}{|l|}{ Random Effects } \\
\hline 2 & \multicolumn{4}{|c|}{0.007} & \multicolumn{4}{|c|}{0.007} \\
\hline \multirow[t]{3}{*}{$\mathrm{T}_{00}$} & \multicolumn{4}{|c|}{0.001 Julian day difference } & \multicolumn{4}{|c|}{0.003 Julian day difference } \\
\hline & \multicolumn{4}{|c|}{0.002 Grid.10km:Expansion } & \multicolumn{4}{|c|}{0.002 Grid.10km:Expansion } \\
\hline & \multicolumn{4}{|c|}{0.003 Expansion } & \multicolumn{4}{|c|}{0.000 Expansion } \\
\hline ICC & \multicolumn{4}{|l|}{0.47} & \multicolumn{4}{|c|}{0.42} \\
\hline \multirow[t]{3}{*}{$\mathrm{N}$} & \multicolumn{4}{|c|}{40 Grid.10km:Expansion } & \multicolumn{4}{|c|}{40 Grid.10km:Expansion } \\
\hline & \multicolumn{4}{|c|}{2 Expansion } & \multicolumn{4}{|c|}{2 Expansion } \\
\hline & \multicolumn{4}{|c|}{51 Julian day difference } & \multicolumn{4}{|c|}{51 Julian day difference } \\
\hline Observations & \multicolumn{4}{|c|}{686} & \multicolumn{4}{|c|}{614} \\
\hline $\begin{array}{l}\text { Marginal R² / } \\
\text { Conditional } \mathrm{R}^{2}\end{array}$ & \multicolumn{4}{|c|}{$0.33 / 0.64$} & \multicolumn{4}{|c|}{$0.48 / 0.70$} \\
\hline
\end{tabular}

Significant $t$ values with a magnitude greater than 1.96 are indicated in bold. $\sigma^{2}=$ Residual variance; $\mathrm{T}_{00}=$ Random effect variance; ICC = Interclass correlation coefficient 


\section{Table 2 (on next page)}

Statistics for two-block partial least squares (2B-PLS) anlaysis for size-adjusted shape variables to environmental variables for forewing and hindwings.

The environmental variable most strongly associated with each partial least square (PLS) axis is indicated with an asterisk. Significant correlations ( $p$-values) using 10,000 permutations are indicated in bold. 


\begin{tabular}{|c|c|c|c|c|c|c|c|c|}
\hline & \multicolumn{4}{|c|}{ FOREWING } & \multicolumn{4}{|c|}{ HINDWING } \\
\hline & PLS1 & PLS2 & PLS3 & PLS4 & PLS1 & PLS2 & PLS3 & PLS4 \\
\hline \multicolumn{9}{|l|}{ Loadings against: } \\
\hline Latitude & -0.18 & $-0.77^{*}$ & 0.55 & 0.28 & -0.16 & $-0.88^{*}$ & 0.20 & -0.40 \\
\hline Years colonised & $0.98^{*}$ & -0.14 & 0.12 & 0.00 & $0.98^{*}$ & -0.18 & 0.05 & 0.02 \\
\hline Dev. temp. & -0.02 & 0.58 & $0.81^{*}$ & 0.00 & -0.02 & 0.17 & $0.98^{*}$ & 0.12 \\
\hline Mean 10yr temp $\left(T_{10}\right)$ & 0.05 & 0.22 & -0.17 & $0.96^{*}$ & 0.09 & 0.41 & 0.04 & $-0.91^{*}$ \\
\hline Covariation explained & 72.96 & 23.60 & 2.73 & 0.71 & 90.92 & 7.41 & 1.5 & 0.14 \\
\hline Correlation between blocks ( $r$ ) & 0.20 & 0.25 & 0.18 & 0.19 & 0.22 & 0.26 & 0.18 & 0.15 \\
\hline Correlation coeff. P-value (perm.) & 0.001 & $<.0001$ & 0.001 & 0.0001 & 0.0002 & $<.0001$ & 0.0012 & 0.02 \\
\hline
\end{tabular}




\section{Table $\mathbf{3}$ (on next page)}

Linear mixed model results for forewing and hindwing basal mean grey value. 


\begin{tabular}{|c|c|c|c|c|c|c|c|c|c|c|c|c|c|c|c|c|}
\hline \multirow[b]{3}{*}{ Predictors } & \multicolumn{8}{|c|}{ FOREWING } & \multicolumn{8}{|c|}{ HINDWING } \\
\hline & \multicolumn{4}{|c|}{ Dorsal } & \multicolumn{4}{|c|}{ Ventral } & \multicolumn{4}{|c|}{ Dorsal } & \multicolumn{4}{|c|}{ Ventral } \\
\hline & Est. & SE & $d f$ & $t$ & Est. & SE & $d f$ & $t$ & Est. & SE & $d f$ & $t$ & Est. & SE & $d f$ & $t$ \\
\hline (Intercept) & -1.16 & 92.93 & 25.07 & -0.01 & 36.95 & 76.42 & 54.41 & 0.48 & 82.14 & 112.92 & 28.97 & 0.73 & -8.18 & 86.91 & 55.81 & -0.09 \\
\hline Latitude & 1.47 & 1.53 & 16.74 & 0.96 & 2.15 & 1.07 & 48.92 & 2.01 & 0.81 & 1.87 & 22.16 & 0.43 & 2.88 & 1.23 & 49.29 & 2.35 \\
\hline $\begin{array}{l}\text { Mean 10-year annual } \\
\text { temperature }\left(T_{10}\right)\end{array}$ & 4.32 & 2.54 & 59.41 & 1.70 & 1.67 & 2.53 & 58.34 & 0.66 & 1.50 & 3.03 & 59.36 & 0.49 & 2.59 & 2.89 & 59.75 & 0.90 \\
\hline $\begin{array}{l}\text { Temperature during } \\
\text { development }\end{array}$ & -2.34 & 1.33 & 38.34 & -1.76 & -3.27 & 1.41 & 38.74 & -2.33 & -1.88 & 1.59 & 37.78 & -1.18 & -3.23 & 1.63 & 39.04 & -1.98 \\
\hline Years colonised & 0.07 & 0.14 & 18.79 & 0.50 & 0.18 & 0.10 & 38.35 & 1.82 & -0.03 & 0.16 & 24.65 & -0.18 & 0.13 & 0.12 & 38.65 & 1.08 \\
\hline \multicolumn{17}{|l|}{ Random Effects } \\
\hline$\sigma^{2}$ & \multicolumn{4}{|c|}{82.56} & \multicolumn{4}{|c|}{88.93} & \multicolumn{4}{|c|}{101.88} & \multicolumn{4}{|c|}{79.46} \\
\hline \multirow[t]{3}{*}{$\mathrm{T}_{00}$} & \multicolumn{4}{|c|}{18.41 Julian day difference } & \multicolumn{4}{|c|}{12.15 Julian day difference } & \multicolumn{4}{|c|}{27.06 Julian day difference } & \multicolumn{4}{|c|}{18.77 Julian day difference } \\
\hline & \multicolumn{4}{|c|}{70.45 Grid.10km:Expansion } & \multicolumn{4}{|c|}{86.82 Grid.10km:Expansion } & \multicolumn{4}{|c|}{101.35 Grid.10km:Expansion } & \multicolumn{4}{|c|}{11.79 Grid.10km:Expansion } \\
\hline & \multicolumn{4}{|c|}{88.51 Expansion } & \multicolumn{4}{|c|}{0.0001 Expansion } & \multicolumn{4}{|c|}{$172.05_{\text {Expansion }}$} & \multicolumn{4}{|c|}{0.0002 Expansion } \\
\hline ICC & \multicolumn{4}{|c|}{0.68} & \multicolumn{4}{|c|}{0.53} & \multicolumn{4}{|c|}{0.75} & \multicolumn{4}{|c|}{0.63} \\
\hline \multirow{3}{*}{ 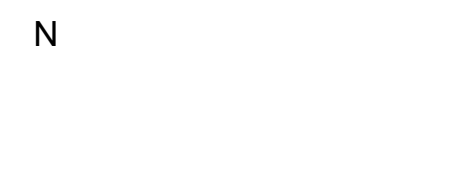 } & \multicolumn{4}{|c|}{43 Grid.10km } & 43 & rid.10km & & & & Grid. $10 \mathrm{~km}$ & & & & Grid. 10kn & & \\
\hline & $2 \mathrm{E}$ & pansion & & & $2 \mathrm{Ex}$ & ansion & & & & Expansion & & & & xpansion & & \\
\hline & & Julian day d & fference & & 53 & ulian day di & ference & & & Julian day & difference & & & Julian day & difference & \\
\hline 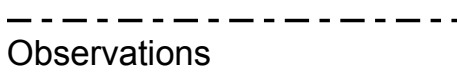 & $--\frac{-}{70}$ & --- & ---- & ---- & $--\frac{-}{70}$ & --- & --- & --- & $--\frac{-}{64}$ & $2--$ & --- & --- & $---\overline{64}$ & $\frac{---1}{1}$ & --- & ---- \\
\hline Marginal $\mathrm{R}^{2}$ / Conditional $\mathrm{R}^{2}$ & 0.0 & $5 / 0.70$ & & & 0.2 & / 0.62 & & & & $03 / 0.75$ & & & & $20 / 0.7$ & & \\
\hline
\end{tabular}

Significant $t$ values with a magnitude greater than 1.96 are indicated in bold. $\sigma^{2}=$ Residual variance; $\mathrm{T}_{00}=$ Random effect variance; ICC= Interclass correlation coefficient 